

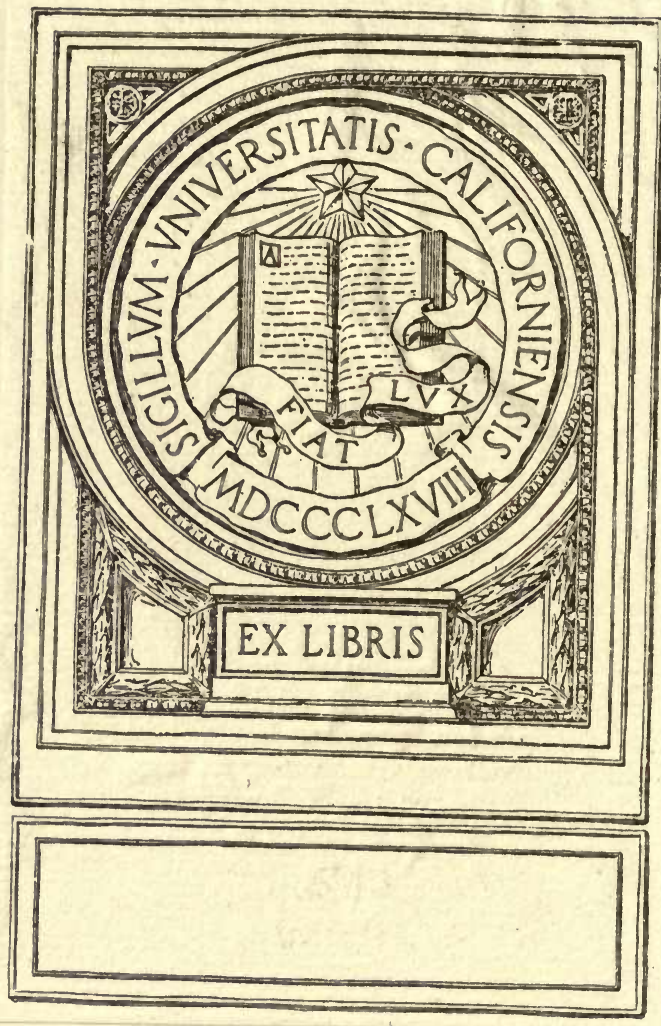




HANDBOOKS OF PRACTICAL GARDENING-VII EDITED BY HARRY ROBERTS

THE BOOK OF VEGETABLES 


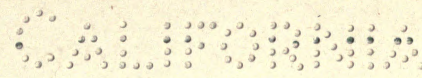

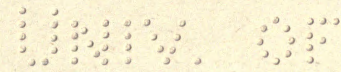


$\because \vdots \quad \because \because 3 \vdots$

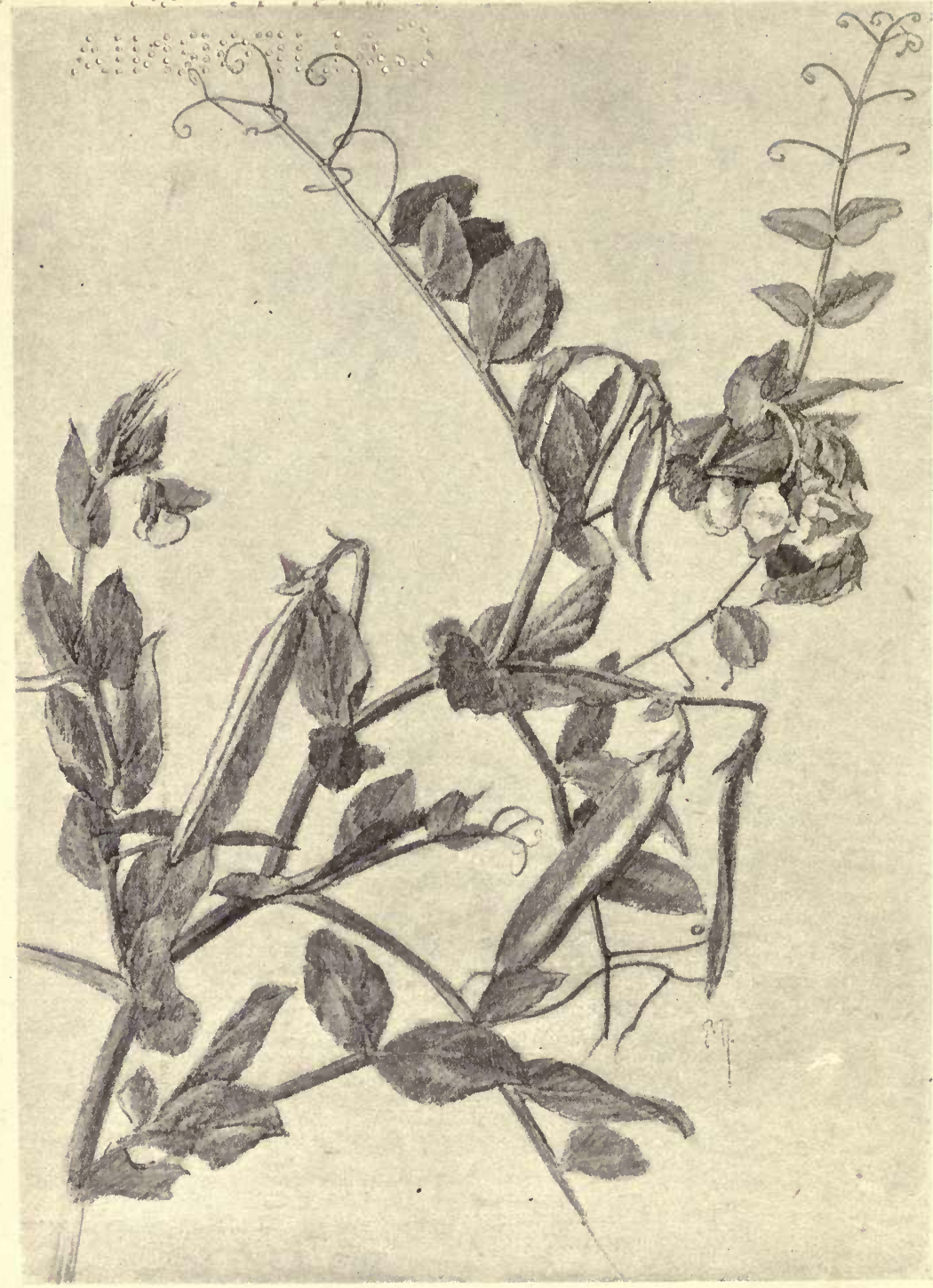




\section{THE BOOK OF VEGETABLES}

BY

GEORGE WYTHES, V.M.H.

HEAD GARDENER TO THE DUKE OF NORTHUMBERLAND, K.G.

TOGETHER WITH CHAPTERS ON THE HISTORY AND COOKERY OF VEGETABLES : BY THE EDITOR

JOHN LANE: THE BODLEY HEAD LONDON AND NEW YORK. MCMII 


$$
\begin{aligned}
& S^{321} \\
& W 9
\end{aligned}
$$

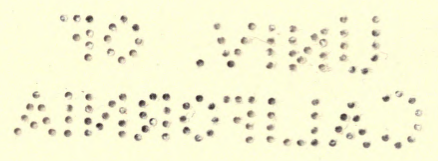

Printed by Turnhull \& Spears, Edinburgh. 


\section{CONTENTS}

Editor's Note . . . . . . . . . . . . $\quad$ xi

The Culture of Vegetables . . . . . . . .

Cabbages . . . . . . . . . . . I I

Broccoli and Cauliflowers $\quad$. . . . 7

Borecoles or Kales . . . . . . . . 13

Brussels Sprouts . . . . . . . . 16

SPINACH . . . . . . . 20

Roots . . . . . . . . 23

BeEtroot . . . . . . 23

Carrots . . . . . . . 26

PARSIPS . . . . . . . 28

Turnips . . . . . . . . . 30

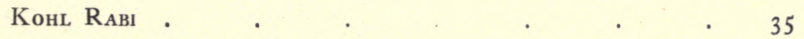

Jerusalem Artichokes . . . . . . 35

ONIONS . . . . . . . . 36

LEEKS . . . . . . . 40

Shallot AND Garlic . . . . . 42

Potatoes . . . . . . . . . . . 43

Peas . . . . . . . . . . 54

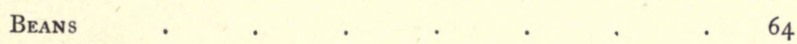

Dwarf Beans . . . . . . . . 66

Runner Beans . . . . . . . ${ }_{\text {vii }}^{70}$ 


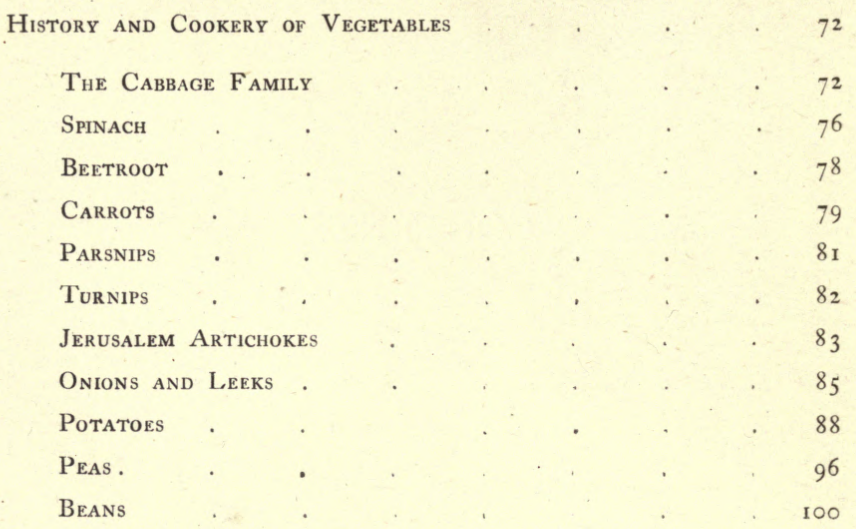




\section{ILLUSTRATIONS}

Study of Garden Peas (from a drawing by Ethel

PAGE Roskruge)

Frontispiece

Cabbage-Wythes' Main Crop .

Cabbage-Kelway's Placebo . . . . . . 5

Broccoli-Sutton's Superb Early White * * 9

Brussels Sprouts-Kelway's Prolific . $\quad$ i 7

Spinach - The Carter

Turnip-Carter's Early Forcing . . . . . 3 I

Potato-Wythes' English Beauty . . . . . 45

Potato-Sutron's Supreme $\quad$. $\quad$. $\quad$. $\quad$. 49

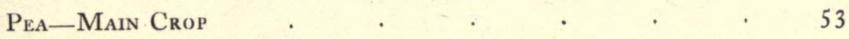

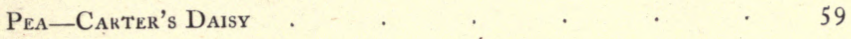

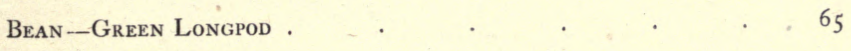

Dwarf Bean-Progress . $\quad . \quad \ldots \quad$. $\quad . \quad . \quad 67$

Amateur's Shed for Storing Potatoes ‘ . . . . 93

OrR's Storing Trays (showing method of stacking). . . 94

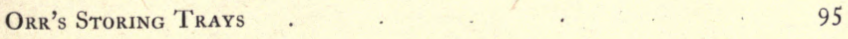

Dwarf Bean-Canadian Wonder . . . . . . 105 



\section{EDITOR'S NOTE}

Mr George Wythes, the author of that part of the present volume which deals with vegetable culture, stands among the dozen leaders of his profession. Like most other distinguished practical gardeners, his career has furnished him with a very varied experience. Descended from a Worcestershire yeoman stock, he received his education at the Queen Elizabeth Grammar School, Worcester. After leaving school, he worked for a time in various large gardens, both private and municipal. Then $\mathrm{Mr}$ Wythes obtained the post of head gardener at Thirlestaine Hall, near Cheltenham; and obtained his first measure of general horticultural fame. From Cheltenham, he proceeded to Lord Hatherton's seat at Teddesley Park in Staffordshire, afterwards taking over the post of head gardener to the Duke of Northumberland, about fourteen years ago. To the Duke's gardens at Syon House, Mr Wythes has added much beauty and fame. Even those who are not familiar with the name of their raiser may have heard of the "Syon House Melon," the "Syon House Prolific Potato," and other similarly named fruits and vegetables.

As a writer on various branches of gardening, $\mathrm{Mr}$ Wythes is well known to all who read contemporary garden literature. For many years he has been a regular contributor to The Gardeners' Chronicle, The Gardeners' Magazine, and The Garden, and an occasional contributor to The Field. $\mathrm{He}$ is a Member of the Fruit and Vegetable Committee of the Royal Horticultural Society, and was one of the original sixty to whom were allotted the Victoria Gold Medal of 
Honour in Horticulture on the occasion of the Jubilee of the late Queen. $\mathrm{Mr}$ Wythes is a frequent and successful exhibitor of fruit and vegetables at the Temple Shows as well as at the various other Meetings of the Royal Horticultural Society.

The Editor takes this opportunity of thanking Messrs Kelway, the celebrated florists of Langport, for their courteous granting of leave to illustrate their Placebo Cabbage and Prolific Brussels Sprouts. He also wishes to thank $\mathrm{Mr}$ J. P. White, of Bedford, for permission to illustrate the excellent shed and storing trays, of which he holds the patent rights.

The vegetables dealt with in the present volume are those most commonly grown in English gardens. Volume I. of the present series dealt with Asparagus, Celery, Celeriac, Seakale, Salsify and Scorzonera. Future volumes will be devoted to the gourd family, and to such lesser grown vegetables as Cardoons and Globe Artichokes. 


\section{THE BOOK OF VEGETABLES}

\section{Cabbages}

IN these notes on Common Vegetables my aim will be to advise as to the best flavoured varieties, the best methods of culture, and the best means whereby an extended season may be obtained.

The Cabbage comes first in my notes, and I am not sure but that the cabbage, next to the potato, is the most useful of the vegetables with which it is my function to deal in this book. With a little timely attention, there is no difficulty in having a full supply of good cabbage from January to December, though I am aware that in many gardens it is none too plentiful in the first three months of the year. I do not think I can do better than to take Spring Cabbage first, for of course this is the most important supply, and the earlier it can be had fit for table the better. But a point crops up in advising as to the seasons for sowing and cropping; the right date, say, for Cornwall, would be wrong for the northern portion of the kingdom. There can be no question whatever but that during the past few years there has been considerable improvement in this vegetable. The large coarse cabbages are now less grown; and in their place we have the smaller compact growers, with better flavour-the last an important point, and one which I am pleased that the Editor puts in the foreground. No matter how common the vegetable, the flavour plays an important part. It may be said that a cabbage can be grown anywhere, and sown at any time, without any 
regard to culture at all; but, the better the cultivation, the better quality the vegetable will possess. In many gardens, owing to the notion that the cabbage will grow anyhow, we often see it infested with aphis, irregular in growth, yellow, and of poor quality.

Spring Cabbage. - The best season to sow for an early supply is from the middle of July till the middle of August, or even until the end of the latter month. An exact date cannot be advised, owing to difference of locality, but, no matter where, it is advisable to make two sowings. It is a common error to sow vegetable seeds as one sows mustard and cress, with the result that the seedlings are much weakened and a check is given from the start. By making two sowings there are greater probabilities of success, as, owing to the season, the earlier one may be too forward, and plants run or bolt. It may be said, Why sow so early? Because if only a percentage of the earliest sowing remain good they are valuable, as they come in at a season when green vegetables, especially those of good quality, are none too plentiful. The later sowing forms a succession, and will give good heads till midsummer. From the last-named date they will not be needed so much, other vegetables, such as beans, peas, marrows, and what may be termed summer vegetables, taking their place. As regards varieties, there is a good Ellams, whilst Dwarf Early Spring is very reliable for July sowing, and, like most of the spring cabbages, is of good flavour. Another very fine type of spring cabbage is that typified by Earliest of All, Sutton's April, and Flower of Spring. Mein's No. I, a cabbage much grown in the north, and a larger cabbage, the Early Rainham, largely grown for market in the west, are good kinds. There are doubtless many others equally good, but the half-dozen named are noted for their good flavour; and for flavour also I would advise Flower of Spring. 


\section{CABBAGES}

Planting should be done early, that is, from the middle of September till a month later. I advise early planting on firm ground; many plants in a rich root run are injured by having made a soft growth.

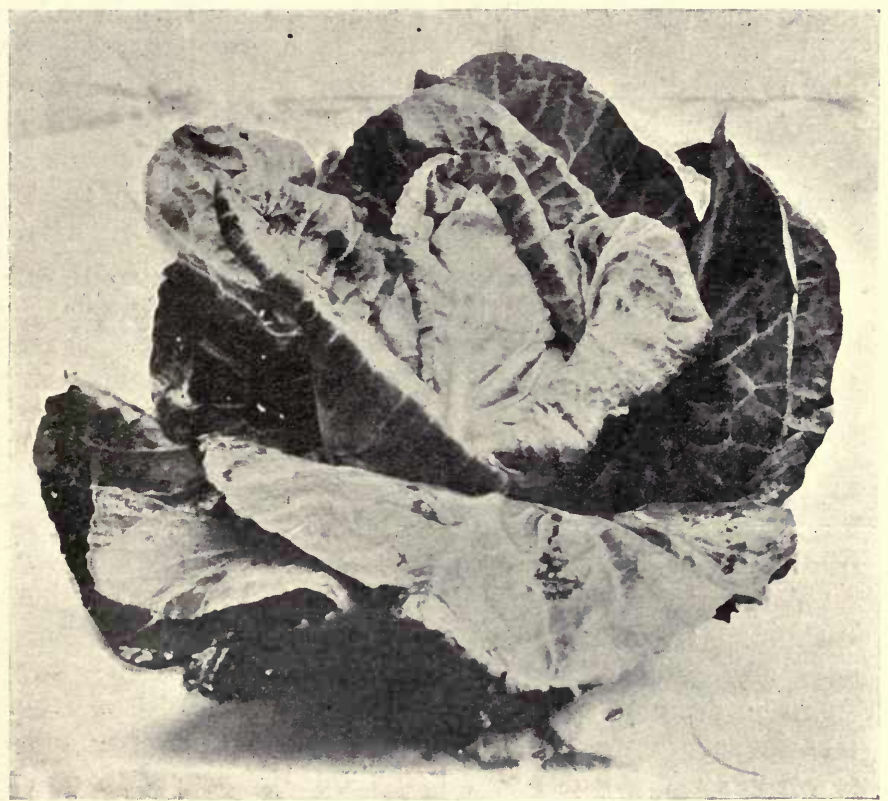

CABBAGE-WYTHES' MAIN CROP

The old method, and one still practised, was to manure heavily, newly dig a piece of land, and then plant. I do not advise this for garden culture, but prefer a firm, hard soil. I find that cabbages planted after spring onions, in soil that has been trodden and rolled for the onion crop, do far better than in newly dug soil, enriched 
with manure, and the reason is patent. The tender seedling, say from October till early in the year, does not need food, and all cabbages are much better grown quickly. To promote a quick growth, food may be given from the surface in the early part of the season in the way of nitrates or liquid manure. Cabbages in rich land, or loose at the collar, that is, not well firmed at planting, make a gross growth, often run badly, and are soon injured by severe weather. That is why I advise a hardier system of culture at the start. Of course, with field culture the plants do not get such rich food as in a small plot of land in gardens; moreover, the situation is more open, the growth hardier, and there are fewer losses. I am afraid that market growers have to study size more than flavour, but in gardens the latter should be the main point. The small varieties, most of those noted above, may be planted somewhat close, fifteen to eighteen inches between the rows, and nine to twelve in the rows, as the produce is cut early. Plant very firmly in light soil, or, what is better, frequently hoe lightly between the rows, but go down each side of the plant and tread or firm the roots in the autumn. In heavy land the last advice is not so necessary, but it is well in all cases to earth up the stems in autumn well into the lower leaves, and to protect in severe weather, doing the work when the soil is not too wet. I may be asked about the second sowing advised. As I intended to note, this is to be employed in case the first fails, and also as a succession. If possible, sow on land that has not grown cabbage for a time. Plant a larger proportion of the August seedlings if any doubts should exist as to the earlier plants bolting, or if insect pests have injured them, or heat and drought weakened them.

Autumn Cabbage.-The Coleworts play an important part in the autumn supply, and these delicately 
flavoured cabbages are not grown nearly as much as they deserve. Sown in May and June, they give nice heads from October to Christmas. There are two varieties mostly grown, the Rosette and the Hardy Green. The latter is valuable for a still later supply, as it may be had in January or later. Comments are often made that our ordinary cabbage lacks the flavour of the colewort, and that frequently is so. The reason

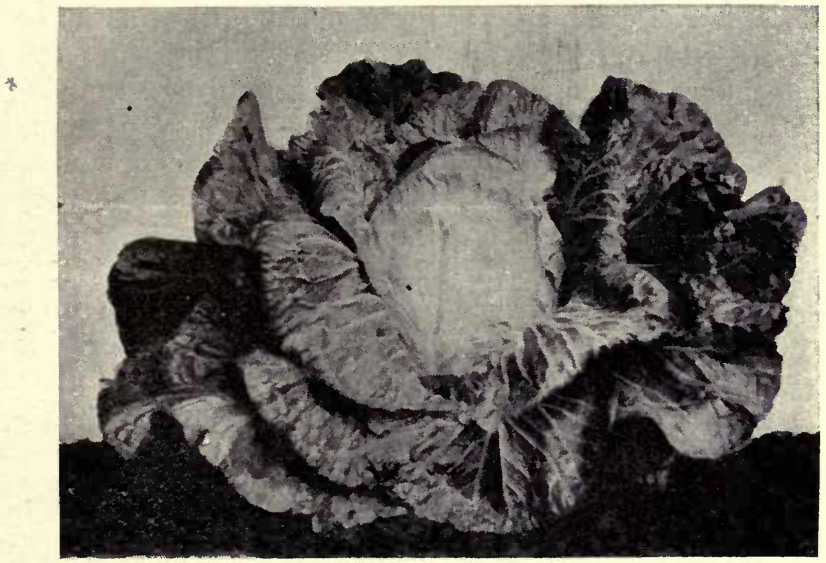

CABBAGE-KELWAY'S PLACEBO

is not far to seek. The colewort sown in summer is fit for use in three or four months, and the growth being made so rapidly tends to improvement of flavour. I am aware that these quickly-grown plants do not stand severe frost, and are best for autumn supplies, as in bad weather when they are solid the hearts of the Rosette section split badly. For later use the Hardy Green, though less valuable from other points of view, makes up for deficiencies. The colewort takes up little 
room and may be planted closer than the spring varieties. There is one point I have overlooked, and that is, a supply from the time the late spring supply finishes until the coleworts turn in. Here such kinds as Main Crop, Matchless, Miniature Marrow, Kelway's Placebo, and Sutton's Favourite are useful; all being excellent summer cabbages. These, if sown in spring, from April till the end of May, will give reliable supplies; they are noted for their good flavour, and should be planted in rich land, as both these and the colewort make their growth quickly, and the same conditions are not applicable as for the autumn planted for spring supply.

Winter Cabbage.-This is a class of green vegetables more neglected than any of the Brassicas. Of course this remark does not apply to the Savoy, but to hardy winter cabbage, of which there are some excellent kinds, though less numerous than of the other classes. The St John's Day is a splendid cabbage for use in midwinter. This should be sown in June, or earlier. It is very hardy, and not soon injured by frost. Another type is Christmas Drumhead, with a flat or drumheadshaped head, very solid, remarkably hardy, and good from December till March. Both these varieties are noted for their delicate flavour, and are most useful. Another winter cabbage is the new St Martin. This is the result of a cross between the Christmas Drumhead and Rosette Colewort, and it is a medium-sized cabbage, having the Rosette flavour with the hardiness of the Drumhead. All the last three types are short-legged, and medium growers. These bring up the supply till the spring. The last-named variety is distinct, and recently received an Award of Merit after a trial of cabbages in the Royal Horticultural Society's gardens. A very few words will be needed to complete my note on this useful vegetable. I have named the Savoy, and this may be made more useful than it often is. 
Sown too early, the heads are often strongly flavoured, badly infested with caterpillar, and not nearly so useful as they might be. These do well for a winter supply. In the north I have kept them good till early in May by growing such kinds as the New Year or Bijou. These, though small, remain solid until late in the spring. For early supplies, the small varieties, such as Green Curled, Tom Thumb, and Early Ulm, are good. These sown in April and May give an early autumn supply. For mid-winter and later, May and June sowings are best. If large heads are required, the Drumhead is the best as regards size, but the flavour is inferior to the smaller kinds grown for late use. A new type, the Perfection, a medium-sized grower, is notable for its good flavour when grown for late use. I have not noticed the red or pickling cabbages. These are best sown in autumn if very large heads are needed, the Red Dutch being suitable. I prefer the smaller better quality, such as Dwarf Blood Red; this does well sown in March for autumn pickling.

\section{Broccoli and Cauliflowers}

I bracket these two useful vegetables together, as they are near relations. At the same time I may be taken to task for including the Cauliflower in my list of common vegetables, but this term must be used in a wide sense, and the Cauliflower can be grown as readily as any other vegetable, and is equally as useful; for, by forcing, the supply may be had ten months out of twelve. The Cornish Broccoli industry is of great value in the early spring, as at that time good vegetables are scarce, and the southern supply fills in a void that is much felt. I am aware that some come from the Continent, but these cannot compete with our own as regards quality. The firm compact white curl of the 
Penzance Broccoli is of excellent flavour, and, owing to the mode of culture adopted, the flavour is distinct from that of those grown in close gardens. Doubtless the hardier the plant is grown the better, and in large areas there are less losses than in sheltered gardens, but, even under the best culture, it is impossible to escape losses owing to severe winters. This is why I advise growing the plant as hardy as possible, for then it suffers less in severe seasons. There can be no doubt of its being a paying crop, far more so than the autumn Cauliflower, as the former is less plentiful, and the Broccoli may be termed a delicious vegetable when not too large.

Culture.-Broccoli culture differs from that of other Brassicas. The plant makes the principal growth in the summer and early autumn, and a strong, sturdy growth should be made by sowing early. On the other hand, too early sowings mean weak plants if the seedlings remain too long in the seed-bed before being placed in their permanent quarters. What then is the right time to sow and to plant, and what the best soil to plant in ? The plants like a heavy loam. The best broccoli crop I ever saw was grown in well-tilled clay land. The autumn and early winter broccoli do not need more than six months, or very little more, to mature their growth; and in gardens I consider the early crop to be an important one, as, though the early winter crop may need protection in the way of lifting into sheds or cellars, the plants treated thus will give a home supply till Christmas. Such kinds as the Self-Protecting Autumn are most valuable if treated as advised. This I have sown in April for Michaelmas supply, and early in May for the later crop-that is, to fill in the gap from late October to Christmas. But this variety by no means exhausts the supply. There are some splendid autumn varieties in addition to the one 


\section{BROCCOLI AND CAULIFLOWERS 9}

named; and the Early Cape Broccoli, grown so largely many years ago, should not be overlooked. There are

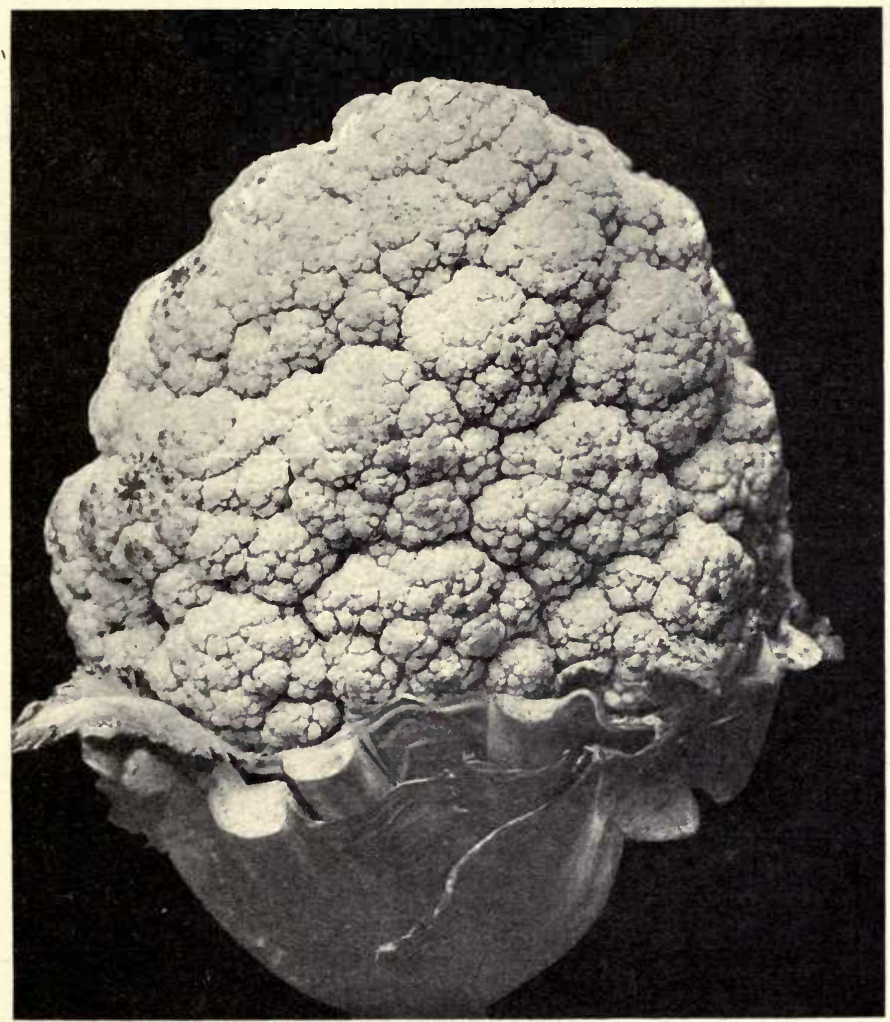

BROCCOLI-SUT'TON'S SUPERB EARLY WHITE

two distinct varieties, the Early White and Early Purple; these turn in during October and November, and are most valuable. The same kind is often grown under the 
name of Grange's Early, and is most reliable for garden culture. Of newer introductions, Sutton's Michaelmas White, Christmas White, and the well-known Snow's Winter White are all good, but the last-named stock is not always reliable. For many years I have grown the Walcheren for an autumn supply, and this with the other varieties noted above will furnish a full crop if sown in April and May, sown very thinly, so that strong plants are secured. What is most important, the seedlings should be planted early, and not allowed to get weak or drawn in the seed-bed.

Winter Broccoli.-We now come to the second division, or what is termed the mid-winter supply. This is less reliable than the earlier, as a severe frost in December or January will cripple the tender growth of plants just forming heads, and the crop will be lost. Hence it is essential to grow those kinds with sturdy, short stems, as they are less susceptible to injury. There are some good selections of winter broccoli. First come the Penzance, a famous Cornish variety, and the Sandringham Winter White, very hardy if the true stock is grown. Unfortunately, broccoli stocks so soon become mixed unless carefully grown, that it is necessary to select with care. Another very fine type for winter is Superb Early White; this has proved one of the best and most reliable kinds we have grown. At the end of the winter the Sprouting Broccoli are most useful, both in the Purple and White forms, the first-named being the hardier of the two, as it is of dwarfer growth and more compact.

Spring Broccoli.-This section provides the supply from March till June, which is a critical period of the year, during which the choice of good vegetables is limited. The seed of these should not be sown too soon; May is quite early enough, providing the seedling plant is not crowded in the seed-bed, and is grown as advised 
for earlier plants in an open position in good land and on holding soil. Fortunately some of the latest kinds, such as Late Queen, Model and June Monarch, are very hardy. To these, to precede them, may be added the old but reliable Cuttell's Eclipse, Carter's Champion, a fine late kind, Miller's Dwarf and Dwarf White. But no matter what kinds are grown, it must be borne in mind that spring broccoli are capricious, and that varieties for certain seasons will often vary, not coming true to season. I do not advise growing too many kinds. It is far better to grow less, selecting those that are reliable, or at least that are hardy, and I find that the largest heads are not the most useful in gardens. It is far better to make two sowings of the late kinds, if quantities are needed-indeed, I would advise sowing for the three seasons noted at different intervals, from February till June, and not as is often done, making one sowing in the spring. It is a difficult matter to advise on the protection of late kinds. The old system of heeling over to the north and covering up the stem has much to recommend it, but this can only be done with garden culture-indeed, with field culture, where the plants are grown more hardily, I do not think this necessary.

Cauliflower. - This plant is even more tender than the Broccoli. It gives the summer and early autumn supplies, and there can be no question as to its usefulness. When well grown it is most delicate; the flavour of small white quickly-grown heads being most liked. As the plant makes its growth in a short time (I refer to the summer crop), it needs richly manured land and not too heavy soil. Few plants suffer more quickly from heat and drought. The best season is doubtless in the late spring or early summer. In the late autumn-indeed, in July and August-cauliflowers are not required, there being a wealth of other vegetables to select from, so 
that my note more concerns the seasons when the plant is at its best.

The old system of sowing such kinds as the Early London and the Walcheren in the autumn (August or early September) still finds favour with many growers, and I find it most reliable, as, if the plants are planted out on sheltered borders in Octøber, or given hand glass protection in winter, there are few failures. At certain seasons the cauliflower buttons-as it is termed in gardening phraseology - that is, the plants prematurely form small heads and are useless. The latter evil is often caused by too early sowing. Now, in the south and west, September is soon enough to sow, and the middle of August in the north. In some gardens planting the seedlings at the foot of a south wall will winter the plants safely; in others it is not safe to plant even under hand glasses. Here other courses are open. It is a good plan to pot up in three-inch pots sufficient plants for an early quarter. These, planted out early in March on a warm border in rich soil, will soon turn in should the weather be genial. The plants in pots are best placed in cold frames at the potting. It is much better if the pots are plunged, abundant ventilation being given in all favourable weather, very little moisture being permitted. When potting, use porous materials well firmed, so as to induce ample fibrous roots. Another plan to obtain early small heads in June, or earlier, is to sow in heat. In January, prick out when large enough into a warm frame or bed in which the heat is partially spent, and then harden and plant out on a sheltered border, lifting each plant carefully to preserve the roots and ball of earth intact; shading and watering as necessary. The best varieties for this work are the Snowball, the Early Forcing, and Sutton's First Crop. Though small, the heads are quite large enough for table, and the flavour is excellent. Another system 
may be adopted with these small kinds, and that is, pot culture. I do not advise it, as better results follow frame culture at the start. To follow these early kinds, either autumn sown or those sown later under glass, such kinds as the Pearl, Dwarf, Erfurt, Mammoth, Purity, and Favourite are good. These, sown in March and April in the open, and planted out in rich ground in May or June, will give a succession. For autumn, the well-known Autumn Giant, the variety so much grown in market gardens, is the general favourite. This, sown in March or April, will turn in at September or October. Being a coarse grower, it needs ample room. Two feet is none too much all ways, and a rich root-run suits the plant. There are other kinds very good. The Autumn Mammoth is of a similar type, and is a good flavoured variety if not too coarse. A trial of the Dwarf Mammoth will give satisfaction where quality is the chief test. Strongly flavoured cauliflowers are not liked, and size does not imply quality. The autumn kinds should be planted early in the spring.

\section{Borecoles OR Kales}

Of late years the Borecole or Kale-the plant being known better by the latter name-has become a greater favourite, and rightly so, as a few years ago, when the winter in February and March was unusually severe, the Kales were the only green vegetables left, everything else having been killed. In Scotland, the Scotch or curled Kale is a general favourite, and, as the plants throw a lot of tender sprouts at a season when green vegetables are none too plentiful, there should be no lack of this useful vegetable in gardens, and few things are grown more easily. The season can be a long one if desired, from October till April. If the earlier supply is 
needed, sowing should be made in March; for the later in May; and the same remarks apply as regards sowing and planting as advised for other Brassicas. But this plant, if needed to give a late supply, should be planted in an open position in firm land with not too much manure. The latter fosters a strong soft growth; whereas a hard, compact one is best for the season named. On the other hand, Borecoles for the early autumn or winter supply need good culture, the growth being made in a shorter period. Where a large supply of green vegetables are required from December to April, the Kales are indispensable, and their value is greater in hard winters, so that good breadths of Kale should be planted for the purpose, selecting the hardest kinds for the late supply.

Culture and Varieties.-I can add little as to culture other than by giving dates of sowing for late and early kinds. For instance, for October cutting, the Sprouting Kales, the Dwarf Green Curled and Sutton AI are very good. The latter is an upright grower, enormously productive and most valuable for early use. These sown in March and planted in May make good progress during the summer. For midwinter there are some excellent selections, and the Read's Improved Hearting is very valuable and very hardy. This Kale may be described as a Scotch Curled, but it hearts in firmly and stands much longer than ordinary varieties. Another very fine variety, with leaves much curled, is the Sutton Curled Scotch, an extremely handsome variety, very hardy and with a mild delicate flavour. Indeed, the two last-named varieties are superior to many vegetables if only they are given ample space and moisture at the start. I find it much the best to sow these kinds for the season named and to plant early, as then the plants get good root-hold and are not so soon affected by heat and drought. There are other modes of culture. If 
the seed is sown early, it is a good plan to prick out the seedlings, six inches apart, as soon as large enough to handle, and later on to transplant carefully to their permanent quarters at a distance of two feet apart each way. In very cold late districts, I have seen the Kales sown in the late autumn and planted out like spring Cabbage either late in the autumn or early in the spring. The autumn sowing secures a much stronger plant, and the plants are better able to stand extremes of weather. The later varieties are equally good, and here such kinds as the Buda or Asparagus should not be overlooked. These are quite distinct from the varieties previously described. These plants produce plain large leaves, and the smooth stem-growths very much resemble Asparagus. Another equally useful is the Cottager's Kale, very hardy and one of the best for producing sprouts late in the spring. A very fine type of Kale is the Welsh Kale, a long branching variety. Other remarkably productive varieties are the Ragged Sack and the Thousand Headed, the latter being much grown in fields. Two new kinds of Kale call for special notice, the Sutton Arctic Green and Arctic Purple. These are the two best Kales for cold, exposed positions, and, as they grow close to the soil, the plants frequently get covered with snow and are not injured. The leaves of the two last-named are curled like the Scotch which they resemble also in flavour. In the northern part of the country these are great favourites. They should be sown in May for a late spring supply in the following season. My note would not be complete without referring to the Variegated Kales. These are most ornamental, and, though the quality is not equal to others, their choice colours make them favourites in most gardens. 


\section{BRUSSELS SPROUTS}

Few vegetables are more useful in their season than this, being of easy culture, and keeping a considerable time when fully grown. I am not an admirer of the very large, loose sprouts that resemble a small Savoy cabbage, as their flavour is not equal to that of the small, hard, compact sprout. There is a great art in cooking green vegetables, and the Editor's notes on this important subject will be read with great interest, for vegetables are spoiled in the cooking more than in the growing. Vegetables do not receive sufficient attention, and fault is often found with the quality when the cooking is to blame. I have denounced the large coarse sprout, and market growers, who value size, as the large sprout soon fills the sieve, will, I fear, not agree with my remarks; but I am pleased to note that even with large growers there is an increasing tendency to grow the medium-sized sprout with a hard bullet-like growth. There is no loss, as a larger quantity of sprouts can be grown on the same space. There can be no question whatever but that the Brussels sprouts is a profitable vegetable if given a long growing season. It may be urged, How can it be profitable when the plants occupy the land so many months? Again, it is urged that the plant needs exceptionally good soil, and will not thrive in any other. This is a mistake. It will do grandly if planted early in land that has been dug deeply, or, what is better, trenched in winter and thrown up roughly. There are many failures, I admit, even with this easily-grown vegetable. One-a common one-is to sow the seed in March, leaving the seedlings in the seed-bed till June or even July, and then planting after a crop of early potatoes. Grown thus, there is not time for the plant to develop, and the result is a small poor sprout not hard enough 


\section{BRUSSELS SPROUTS}

to battle against severe weather. In fact, a quick-growing cabbage would be more profitable than the sprout,

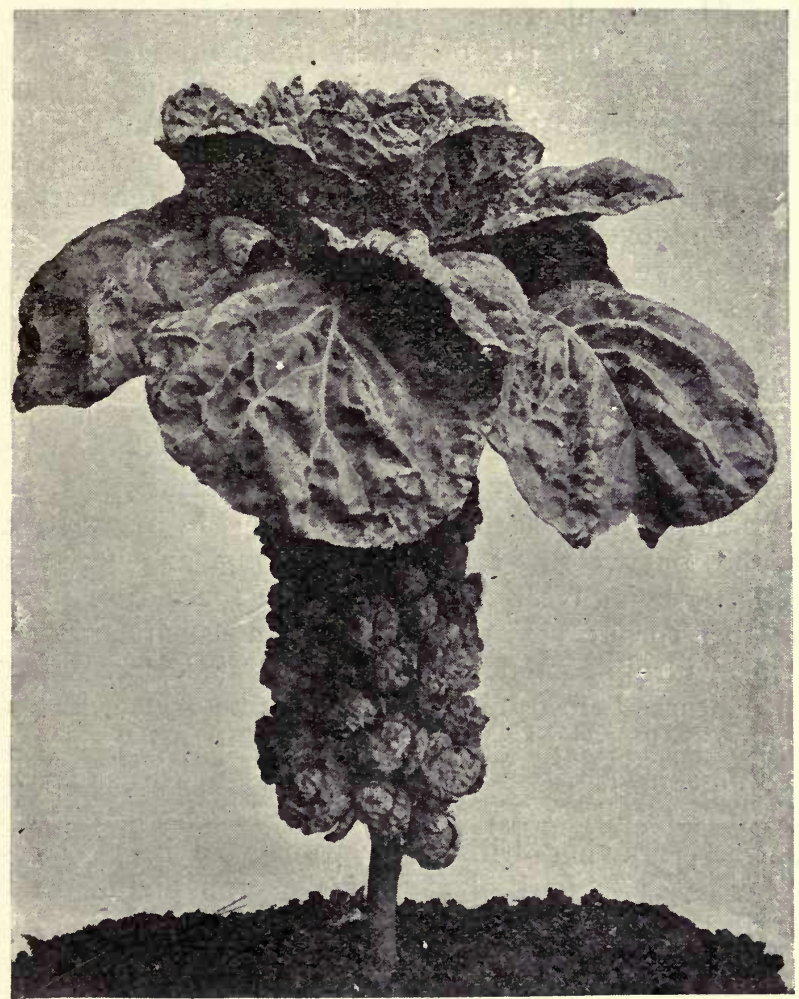

BRUSSELS SPROUTS-KELWAY'S PROLIFIC

which needs more time. Another plan is to plant between a growing crop of potatoes, but this is not fair to the sprouts, as the potato haulm often chokes the plants. 
Culture and Varieties.-Many good gardeners assert that it is necessary to sow the seed in heat or under glass in February or earlier in order to secure a strong plant for May planting. There are diverse views, and a great deal depends on when the plants are placed in their permanent quarters, the state of the soil, and the help given to the plants at the start if the weather is unfavourable. There is no need to sow under glass. I have sown on a warm border late in February in the open, covered with loose litter till the plants were freely above ground, and as soon as large enough, that is, as soon as the fourth leaf showed, planted them in their permanent quarters, first drawing drills so that moisture was readily conveyed to the plants. There is a great gain in this early planting, especially in light soils, as the seedlings get a good roothold before the heat and drought of July cripple the plants. It may be thought that such early planting is a waste of ground, but we sow a single row of spinach between; the latter being cleared off before the space is required for the sprout. Instead of spinach, such crops as lettuce, turnip-rooted beet for early salad, or anything that matures before mid-summer may be used. If land is not at liberty, it is a good plan to prick out the seedlings in April in lines six inches apart, and then to lift carefully with a trowel into their permanent quarters, drawing drills as previously advised. In no case is it advisable to plant Brussels sprouts on land that has just been cleared of a similar crop; I mean any Brassica, especially cauliflower or strong-rooting kales. As previously noted, large gross plants are not best by any means; and frost soon cripples them. I like plants grown as hardy as possible from the start, as if too forward before winter the growth is rank, and the flavour is much impaired. A very good way to obtain early plants for April or May planting is to sow in late 
July or early August, according to the locality, Sow very thinly on land not too rich, in soil that has been well dressed with lime and soot. The plants should remain here till October, and then be pricked out in rows six inches apart in similar soil not too rich, and remain thus till April or May, when they are to be planted out in their permanent quarters. This is a very good plan in late districts on heavy land, and it saves labour in the spring; glass is not needed, and there are few failures. It is also a good plan to make a second sowing late in April if this vegetable is in great demand, as the second sowing, though not equal in produce, will give a later gathering, and the sprouts will be valuable in the spring when choice vegetables are scarce. This sowing may be made in rich soil, as the plants have to make their growth in a short season, and these plants may be grown closer-two feet will suffice-whereas the earlier ones should get three feet.

In previous chapters I have not dwelt on the evil consequences of the pest known as club, but in gardens where the club is in evidence a thorough cleansing of the soil is necessary. So far I have found nothing better than gas lime dressings in the autumn, the land being turned up roughly and the lime broken finely and dug in. Other aids, such as soot, wood ashes, and fresh lime, are all valuable, but not so effective as the gas lime in soils badly infested with any pest that finds a hiding-place therein. In the growing season I have used ammonia; nitrates also are not relished, and for growing crops are worth a trial.

I will only devote a brief space to varieties, as there is no lack of very fine types both for the private grower and the market gardener. The latter will probably not thank any one for advice as to variety, he has his own selections, and market growers often save their own seed, picking out a plant here and there that shows any 
marked advance on the others. In this way a good strain is secured. There can be no question but that the Holborn Exhibition Sprout is a great favourite both in the field and garden, for it is productive, very hardy, and not gross, the plants running from two to three feet, according to the soil, and to when sown. Another very fine variety is Market Favourite, of medium growth and producing fine compact sprouts with splendid flavour. For many years the imported seed had a great hold on the British gardener, but I consider that our own seed houses have a much better type, and a very reliable one. For early sowing, either in autumn or early in the year, I do not know of any variety that can excel the Sutton Matchless, one of the most shapely sprouts grown, remarkably hardy and of splendid quality. The Dwarf Gem may be termed a villa garden variety. The solid build of the plant and its close growth make it most valuable where room is none too plentiful. It is most useful for latest supplies, and not so soon injured as are larger varieties in bad winters. Kelway's Prolific is also good and handy.

\section{SPINACH}

This cannot be called a popular vegetable in small gardens, but few vegetables are more deserving of space, as it can be grown so readily, and is often advised for those who cannot digest more solid vegetables. With a little management spinach can be had all the year round, though there are difficult seasons, such as the early spring. At times the winter checks growth, as north-east winds after frost shrivel up the soft, tender leaves. But there is no difficulty in having good spinach from May till July. In July and August, heat and drought are not conducive to good growth. The plant will not thrive with moisture lacking, but at 
this season a full supply may be obtained by growing the New Zealand variety. This, sown in frames in March and pricked out two feet apart in rich soil in May, will give a full supply from July till September or later. It will also do if sown in fine, rich soil early in May on the open border, the plants, when large

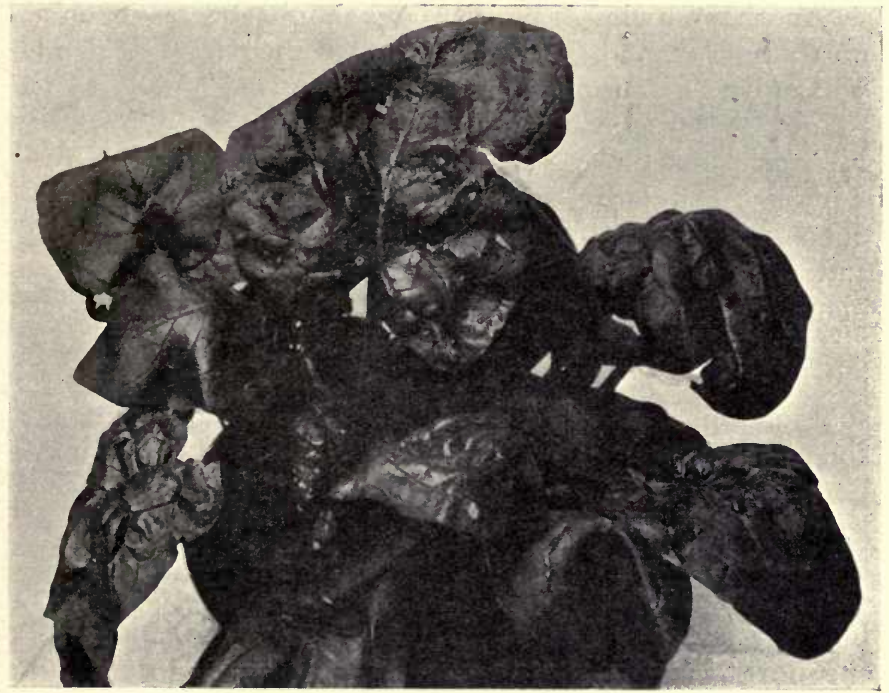

SPINACH-THE CARTER

enough, being severely thinned. In appearance this spinach resembles the ice plant; it is less bitter than the ordinary form; the shoots are gathered, not the leaves. The culture of the older varieties, of which the Carter and Round-leaved Victoria are the best, is simple. The first sowing may be made in February on a warm border. We sow between rows of early peas, 
the spinach never being allowed to remain too long, but cut as ready, and the roots cleared. If allowed to seed, it robs the pea crop, and looks very unsightly. Later sowings are best made in the open. Here we sow in rows a yard apart, and later on plant between the rows a row of Brussels sprouts for early winter supplies.

Another sowing, say in May, should be made on a north border, and after that is past the New Zealand will give a supply. It will thus be noted that, to get a succession, several sowings are made from February to June, say every three weeks, and for winter use a large sowing is made in August on an open quarter in land free from wire worm or grub, and well enriched with manure. A good distance for planting is eighteen inches between the rows, half that distance being allowed in the row. Few plants do better if the soil is made suitable. The use of salt, soot, and lime will give a clean root run, and in poor soils such aids as nitrates, potash and other foods may be used to advantage. The old plan of sowing the Prickly-leaved Spinach for winter and spring supplies is not followed nearly as much as it used to be. The round-leaved and the others named above are equally hardy if sown early enough to make strong plants. In the northern part of the country it is well to sow in July. I have also grown spinach under glass for early spring supplies. The plant illustrated is the new Carter, a very fine fleshy-leaved variety. Another variety, the Spinach Beet or the Perpetual Spinach, is invaluable for cold soils or late districts. This grows like a beet, and the leaves are good though lacking the quality of the other varieties. To get the best leaves, sow in May or June for a winter and spring supply in rows eighteen inches apart, thin the plants to nine inches, give good land to get large leaves, cut over frequently, and do not 
allow the plants to get too large before thinning. This plant is very hardy, and is valuable if the better spinach runs short.

\section{Roots}

Under this heading comes a series of vegetables that are valuable for their keeping properties for winter supplies and for flavouring purposes, and I have placed several kinds together, as they need similar culture. Beet may be thought to be more of a salad than a vegetable, but used as a vegetable in the winter months it is very acceptable. Carrots are needed daily in most houses, and will repay good culture. On the other hand, parsnips are less liked, but much may be done to make them palatable, and turnips are general favourites at most seasons of the year, so that my aim will be to note the best for a year's supply, with a few cultural details.

\section{BEETROOT}

The turnip-rooted beets are valuable for summer supplies, but I am inclined to think that none of the turnip-rooted section can approach the long-rooted variety as regards flavour. This is easily accounted for, as the long rooting kinds obtain more moisture from the soil, and are not so readily affected by climatic changes. The beet may be used in several ways, either as a vegetable, a salad, or a pickle. As a vegetable it may be served in diverse ways. It is excellent served as fritters, and can thus be eaten by many who complain of its being indigestible in other ways. The cultivation is most simple, though it does best in a good friable loam. On the other hand, the soil should never get any rich food just before sowing, as it causes grossness and bad shape and colour, and affects the flavour. 
However, this plant does well in land that has grown celery or been well manured for a previous crop. In gardens near the coast I have seen sea-weed used as manure for these roots. The weed is laid spade deep at the bottom of the trench when digging in the winter, and beet grown thus is excellent as regards flavour. Salt used during growth imparts a nutty, sweet taste which many persons are very fond of. There are other advantages in using salt as a surface dressing in showery weather, for it keeps down weed growth, and beet grown thus is often of splendid colour. Beet is much hardier than many persons think it to be. There is no necessity for lifting too early in the autumn, as a little frost is harmless; but there is more need when the roots are lifted to see that they are stored in a cool place not too dry or warm. Once the roots grow out badly and get soft or shrivel, the flavour is greatly impaired. I have found the best store to be a north shed, the roots being well covered with soil, sand, or fine ashes, in severe weather some loose litter being used as a protector. Many do not even store thus if they have large quantities of roots, but bury in clamps like potatoes, and the roots are better than when placed in a dry place.

The turnip-rooted, of which the Crimson Ball is a splendid type, being highly coloured for this kind of root and of good quality, may be sown early in April in a warm, well-drained soil, and if given food during growth will mature very quickly and be valuable for early summer supplies. I have also sown this variety under glass, and then pricked out on a warm border, which gives a gain of at least three weeks over the first sowings in the open. There are other fine Globe Beets, such as Sutton's Globe and Dobbie's; the latter being the best flavoured roots I have tasted. The older Egyptian turnip-rooted are not to be compared as 
regards quality with those noted above; and, though I have only touched upon the value of the turnip-rooted kinds for early supplies, they are equally useful if sown twice or three times during the season in land that is poor, shallow, or stony and unsuitable for the longer roots. Sowings may be made in April, in June, and in August, and thus provide a succession. The kinds named are not gross growers. They do not require too much space; twelve to fifteen inches apart will suffice, with half that distance between the plants. Thin early to prevent the roots being disturbed, and do not allow them to remain on the land in the summer when full grown, but store in moist earth under a north wall. The colour is affected in hot weather if the roots are full grown and the soil is light and dry. The most useful section, the long-rooting kinds, should not be sown too early, May being quite soon enough. The previous remarks apply as regards soil and cultivation. These roots do best with ample room. Fifteen to eighteen inches between the rows, and half that distance between the plants is none too much, and the plants benefit greatly by liberal supplies of liquid manure in hot, dry weather. I recently saw some wonderful crops of beet on land that had a perfect system of irrigation. As regards variety, I do not think that any root comes up to the Cheltenham Green Top. Many years ago I first exhibited this variety at a Vegetable Conference of the Royal Horticultural Society at Chiswick, receiving an Award of Merit, and since then, I am pleased to note, it has become a standard variety. There are other beets more shapely, but none superior in colour or flavour, the latter an important point. The variety named does best in rather poor soil; if at all rich the root grows too large. It should not be sown early and should be given an open position. There is no lack of varieties. Most of our leading seed firms have their own selected 
Blacks and Reds. For exhibition purposes few varieties can beat Pragnell's for its shape and smooth build; other good old kinds are the Pine Apple, the Old Dwarf Red of Nutting's, a good quality beet, and the Crimson, a root largely used for bedding purposes, and of good flavour. For many years I have grown this root specially for latest supplies in the spring, as it keeps sound longer than larger roots. Where beetroot is in demand all the year round, this is a most useful root if stored late, and it needs less room even when growing than do the turnip-rooted varieties.

\section{Carrots}

These roots have their peculiarities. They are not at home in all. soils, but often soils can be made suitable for the roots, and means taken to clear the earth of various pests that spoil the crop. They delight in a sandy soil, not too dry, and need not be sown nearly as early as is often advised. To do them justice, they should be divided into three sections, the short stumprooted or forcing varieties, the early Short Horn or Gem type, for early outdoor crops, and the main crop, or intermediate and long-rooted section. Few roots are forced with less trouble, and certainly small, sweet, carrots in the spring afford a welcome dish. Of early carrots in the open there is ample choice, but I do not think that the short stump-rooted kinds, that are so largely grown for the Paris markets, can be beaten. These roots do not equal the Gem or Model in appearance or quality, but then the latter are much later, and earliness is a great point in May or June. The land should be good for the roots, as the growth has to be made in a short time, and the food for the short-rooted kinds should not be too low down, but merely forked in on the surface; indeed, my best results 
in raising early supplies have been obtained by using a rich old marrow or cucumber bed as a surface-dressing before sowing the seeds, the first sowing being made in the latter part of February or early in March, according to the season and locality. Only a small sowing is needed, using such kinds as Sutton's Gem and the Scarlet Horn, or Model. The second sowing in April will provide a midsummer supply, and the roots may be kept good for a longer time by lifting and treating as advised for summer Beetroot. We now come to the main crop supply, and these roots are needed from autumn to spring. They may be sown late in April or early in May, according to the locality. Sow in drills twelve to fifteen inches apart, allowing half that distance between the roots when thinned. The intermediate sections do well at twelve inches, but the larger ones re- quire more space. I do not advise land newly manured, but deeply dug and in good workable condition. This root is fairly hardy, and in light land not infested with wire worm may be left in the ground and lifted as required for use. To this there is the serious drawback that in severe weather it is difficult to get at the roots. On the other hand, the roots should not be stored in too wet soil, or the crowns decay badly. In land infested with wire worm, gas lime or the refuse from mustard mills should be used in winter, also liberal soot dressings, lime, wood ashes and other charred refuse. Change the quarters yearly, not sowing near other crops that are attacked by these pests, and use less animal manures, relying on liquid and surface dressings during growth.

We make a fourth sowing, and this bears out my remark as to the hardiness of the roots, as this sowing, though the roots are small, is left in the soil all the winter. Needing small roots daily, the roots of the main crop are too large for our purpose. Again, there is a great demand for young carrots in spring, a greater 
demand than can be met by glass culture, so in June or early July we thoroughly prepare a small quarter by soot, lime, and other additions, and sow the Early Nantes in rows nine inches apart, not thinning very hard. These roots are then drawn from December to May, as needed. They are small, but sweet and good, and only make a very small top growth. In severe weather long litter or bracken is loosely thrown over a portion of the beds to facilitate lifting. The chief drawback to these late sown roots is that in hot dry summers the seed is some time in the soil before it germinates, so that it may be well in late districts to sow at the end of June. In all cases it is necessary to sow in clean land. In winter the roots are most liable to the attacks of the various pests alluded to above. I have not named the Long Red Surrey type of carrot for garden work. In fields the Altringham is much grown for market, but I think the intermediate types, such as James or Scarlet, are superior. There are white varieties, such as the White Belgian, but they are not popular in this country. Those roots having a small core are the best flavoured.

\section{Parsnips}

Few roots are more productive than the Parsnip, and, though I shall not advocate the general culture of roots, as sometimes seen at shows, quite two to three feet in length, I do not think that this vegetable is valued enough, as it is one of the hardiest, and very wholesome. There are objections to large coarse roots. They have a lot of core, and must be cut into pieces to cook them properly, and thus the flavour is lost. Much better results follow when the roots are grown in a shorter time, and only of such a size that they can be cooked whole. I find the roots are much better when 
a spell of cold weather or frost has checked growth. But these roots, like others, should not be dug too early or stored in a warm place. If possible it is best to leave them in their growing quarters and dig as required, or they may be lifted and clamped like potatoes; but care should be taken to throw out all diseased roots, and to store in well-drained quarters. Of late years some valuable varieties have been added, such as the Tender and True.

There are not, however, many varieties. Doubtless the best are the one just named and the Student, if flavour is valued. For mere size, such kinds as the Hollow Crowned and the Maltese and Jersey Marrow may be grown. These latter are much grown for exhibition. Few plants are cultivated more easily. In all cases it is necessary to dig the soil deeply, and this is best done in the winter months; indeed, trenching is necessary for large roots. It is also well to make the soil rich and friable, and I have seen an iron bar or large dibber used. This is forced into the ground to a good depth, and the large hole made is then filled in with rich soil, such as an old manure bed or rich fertilisers, and a few seeds dropped in each hole, the seedlings, when large enough, being thinned so as to leave the strongest. For very large roots, seeds are sown in February when the weather is suitable, but I find that the best eating roots are those sown in May. They are large enough for all purposes, though the market grower would not find them so profitable, and would find it pay best to sow in March. When sown in the ordinary way, fifteen to eighteen inches between the rows will suffice, half that distance being allowed between the plants. In poor soils I have found the roots of better flavour if given some fertilisers during growth, and the food well washed down to the roots. In most soils the seeds germinate so freely that thick sowing should be avoided, 


\section{TURNIPS}

This vegetable may be had in season all the year round, though it is not at all plentiful from March to May. Of course, in fields there is no lack of these roots if clamped, and we may in a measure take a hint from the large grower, as in gardens the roots of the early summer sown are poor and flavourless at the season named. It may be said that the demand is not great at the difficult period noted, but I find that small, sweet, good-flavoured turnips are always in demand. It is useless to sow in summer, and expect this sowing to last till the next spring. Such roots are too coarse; they soon grow out, get soft, and are flavourless. On the other hand, young turnips may be had much earlier than is often attempted. The long-rooted variety here illustrated, Carter's Early Forcing, is admirably adapted for early supplies. This, sown in February, the quarter being covered with dry litter at night or in cold weather, will give nice roots early in the spring. It is a remarkably quick growing variety, and is good for frame culture, as it may be had in April in a warm frame. I have referred to this variety, as it is even earlier than the Milan types, which are much liked on the Continent, and are among the best for first crop in the open. Both the Red and White Milan should be eaten as soon as they are large enough to use, as these varieties so soon lose flavour.

There are other early kinds, such as the Early Paris Market, a stump-rooted variety largely grown in France. For June or July supplies, I do not know of any turnip equal in all respects to the shapely Snowball, a white early root of great merit. Again, the White Gem is not unlike the forcing turnip that is illustrated. It is a splendid root for summer 

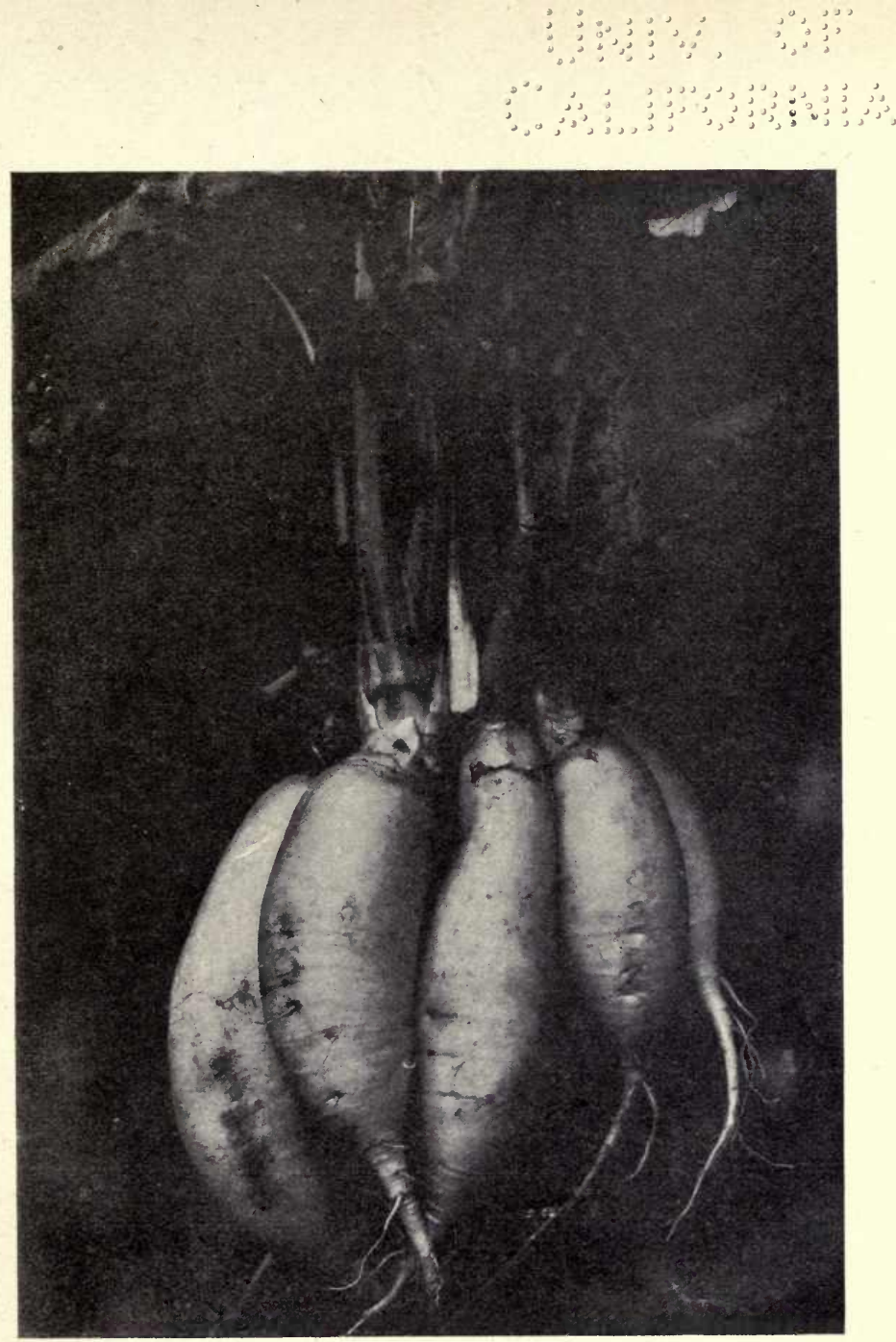

TURNIP-CARTER'S EARLY FORCING 

work, and does not feel the effects of drought so soon as do the flat roots. There are some very fine roots to select from. The Red Globe is a beautiful late summer variety; and to this should be added the Matchless and Criterion.

We now come to the autumn turnips, doubtless the most valuable roots of the season, as these give a supply from October to March, or even later if good storage is adopted. The Red Top Mousetail or Strapleaved is good for the early autumn, and none is better than Veitch's Red Globe, a very fine solid root that keeps well for months if not grown too large. For keeping purposes, small or medium-sized roots are much the best. For mid-winter such kinds as the Orange Jelly and Yellow Maltese are remarkably hardy. These will stand in the open without protection if sown for late supplies. To these should be added Golden Ball, a beautiful root. These yellow-fleshed turnips are not demanded nearly so much as they should be. The flavour in winter is very delicate, and they make a nice addition to the white varieties. The older Chirk Castle, or Black Stone, may be termed a winter turnip; it has a black skin, but is not bad flavoured, and is a very fine winter turnip in heavy soils.

Culture.-The best roots are those grown in a sandy loam, well dug and manured with decayed manure some time in advance of sowing the crop. For very early roots, a south border under a wall is a good place; and here I would advise, if the soil is clayey or wet, adding some light material, such as burnt refuse. Soot and lime may also be added if slugs are troublesome. Make the land as fine as possible before sowing the seed. The second sowing may be made in an open quarter, and the plants thinned as soon as large enough to handle. At this season, should the weather be hot and dry, the grower's troubles begin, as the seedlings are very 
subject to the attacks of the fly, though damping overhead in the evening, with soot or soot and lime dusted over the plants when in a damp state, will check its ravages. This root does not like drought, so that summer crops may occupy a heavier soil than earlier ones. For summer roots, a space of twelve inches between the rows should be given, and the seedlings thinned to half that distance, and kept as clean as possible during growth. I have previously referred to the importance of early thinning, as in summer the root bulbs quickly, and once this has commenced it is not advisable to loosen the roots.

I now come to the autumn sowing. This should be done from the early part of August to the end of that month, though in cold or late districts late July sowings may be necessary. Those late sown roots will not be large, but they will be large enough for all purposes. Far better get a solid small, sweet root than a large, soft and worthless one. If ground is available, sow on a well-drained quarter, as there will be no need to harvest this crop till late in the year. Then one need merely select the large roots, and place them under soil to be just frost-proof, leaving the smaller ones to take their chance. These take no harm if the soil is hoed over them each side of the row. The roots left out have their use as a green vegetable in the spring, as they produce the tender green tops so much liked at that season. The yellowfleshed kinds and the Chirk Castle are specially good for the latter purpose. In storing roots for winter, select a store just free from frost-indeed, I have placed the roots in heaps in their growing quarters, and well covered them with soil to ward away frost. Turnips should never be allowed to remain on the soil if at all diseased, but cleared away, and only the sound roots stored. The land should not be re-cropped with 
this root for some time, and a good dressing of lime should be given after the roots have been removed.

\section{KoHL RaBi}

This vegetable so much resembles the turnip that I include it in my note on roots. Though not a general favourite in this country, it is largely grown on the Continent. I have alluded to the difficulty of growing the turnip in hot weather and in light soils. Under these conditions the Kohl Rabi is most useful, as the roots, both in shape and flavour, resemble the turnip, and they are not so readily affected by hot weather. There are only two varieties, the purple and the green, the only difference being in the colour; the Early Purple Vienna is a useful garden kind. In India, Kohl Rabi is much grown for use in soups and for flavouring. Much the same culture is needed as for turnips. Seed should be sown twice during the season to get a succession of roots, an early sowing in March to produce a midsummer or even earlier supply, and another sowing two or three months later to provide an autumn and winter supply. The seed should be sown in drills eighteen inches apart, and the plants thinned to nine inches in the row. These roots should be grown on the flat, so that they may get the rainfall in the growing season. I have transplanted the seedlings with success when they have not been allowed to become too large, lifting carefully to prevent the roots breaking. The same kind of storage as advised for turnips will be suitable when the late crop is full grown, as, if left exposed, severe frost splits the roots.

\section{Jerusalem Artichokes}

The common Artichoke may with advantage be included in my note on roots, as it is very useful for soups 
and as a vegetable. The old rugged purple form was the only variety grown for many years, but, fortunately, the Messrs Sutton, after patient selection, obtained the white, smoother tuber, which is a great gain both in shape and flavour. The peculiar flavour of these roots is not liked by everyone, but by those who have studied the cooking it may be made a delicious vegetable. For some years I have carefully selected the most shapely tubers, as it is important to get the eyes shallow, and so cause less waste in the cooking. I have also by selection obtained a long, smooth white root called Veitch's Improved, which is a great gain on the old purple form. These roots are often grown in any outof-the-way place, and allowed to occupy the same ground year after year, but like all, other vegetables they well repay good culture, change of land, and a good supply of food. The sets should be planted in February or March, and need ample room, a yard between the rows being none too much, with half that distance between the plants. They are often given less room, but this should not be. The roots are best if left in the soil and lifted as required, or the whole crop may be clamped, the best seed being selected for planting.

\section{ONIONS}

Of late years, the onion has received more attention from growers, some magnificent roots being now grown in this country. With more attention to culture we could grow bulbs equal to any grown on the Continent. There is no need to import these roots, and I am pleased to see their extended culture. To get the extra fine roots referred to above, of course special culture is needed. Many sow the seed under glass at the start and grow on, finally planting in the open in very rich soil. 
During growth the plants should have ample supplies of liquid manure or approved fertilisers. Another plan is to sow in the autumn the ordinary spring varieties, such as Ailsa Craig or similar large varieties. But most of our old kinds, such as Bedfordshire Champion, will make very fine bulbs if given special cultivation, by sowing in the early autumn, in land specially prepared. The young plants are planted out in quarters very highly manured early in the year, and the seedlings kept clean, giving the plants ample room, eighteen inches between the rows, and nine inches apart in the row. Many of our best cultivators make a special compost for exhibition roots; deep drills are drawn, in which some rich food, such as soot or fowls' manure is placed; over this being placed some of the best soil, and all made firm. The bulbs being very carefully lifted from their previous quarters, the roots are spread out, and enough space left in the trench to admit of liquid food and water. The onion is so useful as an article of food that, both as a salad plant and for flavouring, it is in great demand; but the larger bulbs I have referred to are most useful as a vegetable, few vegetables being more wholesome. In many gardens this crop is not well managed, but at times it is not the grower who is wholly to blame, as the seasons and numerous pests to which the plants are subject, are responsible for much. Drought, too, is harmful, and to get the best results early sowing is advised; it is necessary to get the quarter ready as early in the winter as possible, as then the land is in better condition. In heavy clay land the soil is not always workable at the season advised, and in such land it is well to add lighter materials. This allows a more fibrous root growth, and gives finer bulbs. The ordinary system of culture is to sow on land well worked, which 


\section{$3^{8}$ THE BOOK OF VEGETABLES}

should not have grown a similar crop for some seasons. Land is supposed soon to sicken of onions. This depends a great deal upon culture, but there is no question whatever that fresh quarters will do much to ward off disease. I have seen many acres of this vegetable destroyed by mildew in wet seasons simply through neglect, not thinning, and sowing too thickly. The grub is one of the most troublesome pests the crop is subject to, especially in its early stages. But I have rarely seen the plant troubled with this pest when sown early and the seedlings transplanted. Another remedy is to use salt, soot, and wood ashes freely, and in old gardens it is a good plan to give dressing of gas lime, say in October, and turn the land up as rough as possible, frequently forking over the surface early in the year to sweeten and pulverise the soil. It is far better to clear the land of the pest than to give remedies during growth. The latter are seldom successful, though such aids as soot and salt during growth will benefit the crop.

Spring Onions.-I will take these first, dealing only with medium-sized bulbs for general use. As regards date of sowing a great deal depends upon the locality and state of the soil. If the latter is light the seed may be sown at the first favourable opportunity towards the end of February, the soil being made as firm as possible either by rolling or treading. A firm root hold for these plants is desirable, and many good growers tread the land over after sowing. In heavy land more care is needed; the labour is greater in preparing the bed, and often seed sowing is deferred till the soil is sufficiently dry. The drills should be shallow, and may be from nine to twelve inches apart. The latter space gives the plant a better chance, and thinning, weeding, and feeding is done more readily. In covering the seed, many give a better compost in 
heavy land, such as the soil from old marrow or cucumber beds, the siftings of the potting bench, or any fine charred refuse. I have also seen sand used to advantage in wet, heavy land, but it should be borne in mind that the soil under should be well manured, the onion needing much food. Early thinning should take place, doing the work in showery weather if possible; but the seed is often sown much too thickly, as in these days there is less need to sow thickly, seeing that seed from a good house is always reliable. The trials it undergoes before being sent out are much more severe than formerly. I have referred to feeding, and few crops benefit more by surface dressing than does the Onion. Nitrates are valuable, as also are fish manure, guano, soot, salt, and liquid manure whenever the latter is obtainable. One of ten sees miserable crops from want of food, late sowing, and neglect. As soon as the seedlings appear through the soil, the hard crust should be broken by gently hoeing between the drills. This will check weed-growth, and as soon as the seedlings are large enough to handle, thinning should take place. It may not be desirable to thin to the required distance at the first, merely thinning out where the plants are very thick, and making a second thinning when it is seen which plants take the lead. The plants at this second thinning will be useful for salads. In using the hoe, care should be taken that the permanent plants are not loosened. On the other hand, severe thinning for what are termed medium-sized bulbs is not advised, and at the final thinning a few rows may be left for salad, or, what is better, another sowing may be made for this purpose in May. These also are valuable for pickling.

Autumn Onions. - These are sown from the middle of July till the middle of August. Much depends upon the variety. I prefer to sow the White Leviathan and Italian at the end of July These do not keep so well 
as some kinds, but they are most valuable for spring use, and as they bulb early in the summer they are more valuable. The Giant Rocca types are notable for their size, colour, and good flavour. These are milder than others, and are excellent for cooking whole as a vegetable. There are several varieties, and all are good, in the-Rocca section, but I must not omit the small Silver Skinned varieties and White Queen. These are much liked for their delicate flavour. Much the same advice holds good as to distance and soil, but the latter need not be so highly manured, as the seedlings remain in the seed bed till February or March, when they are planted out in rows twelve to fifteen inches apart, and nine inches apart in the row. The autumn sown onions are not keepers, but, on the other hand, the spring sown should get cool storage; for cold does no harm if the bulbs are not damp. I have suspended them when roped to the roof of an open shed. If in rooms, they should be laid thinly on racks, so that the air can circulate freely round them, and they should be often turned to keep the bulbs dry.

\section{LEEKS}

The Leek, like the Onion, has of late years found more favour among growers, and is now a favourite exhibition vegetable, but, whilst valuing the improvement made, I am not sure that when the leek is grown nearly a yard long it is as useful as a thick, short plant such as the Lyon, with from six to nine inches of blanched stem. To get the leek of a large size it is often sown in heat or under glass, as advised in order to obtain large onions, but excellent produce may be obtained by sowing in February on a warm border, planting out in trenches with ample manure as soon as large enough to handle. On the other hand, in heavy soils or cold 
situations it may be well to sow a box of seed in a frame for an early supply. These, pricked out in rich soil later on, and then transplanted early in the summer into the trenches, will provide an early autumn supply. For late supplies, indeed, for any season, it is not necessary to plant in trenches. A richly manured quarter on the flat will grow good plants, but it is well to draw drills, and at the time of planting to be careful to spread the roots out evenly. If a dibber is used, care should be taken to make the hole large and deep enough for the roots, to prevent doubling up. I think that under any circumstances it is advisable to make two sowings in boxes-one early, and one, say six weeks later. By this means leeks may be had from October till May-a long period-and, even if not liked as a vegetable, they are most useful for flavouring. The leek should be planted in an open position, and should never lack food or moisture in the summer months if size is needed. Planted on the flat in drills, they should be eighteen inches apart, allowing half this distance between the plants; indeed, in Scotland, more space than this is often given in order to allow of earthing up the stems in the winter to blanch them. If the plants are in trenches the latter should be two feet apart, and a good coating of decayed manure should be placed in the bottom before planting. Few plants are more hardy, as, though the points of the leaves may be touched by frost, it does not harm the stem; indeed, cold appears to give a delicate flavour, and the latter is also improved by salt dressings in damp weather. For hardiness, the Musselburgh is one of the best, and, what is more important, the flavour is mild, even when the leeks are not given the best culture. Other kinds are the Holborn Model, one of the largest and longest leeks grown. Prizetaker also is a splendid variety, and the Ayton Castle Giant is not unlike it as regards size. The last 
three varieties named are the best for exhibition. I need not dwell upon varieties, but would add that few plants are more valuable in cold districts, as the leek winters well when others fail.

\section{Shallots and Garlic}

The first-named are so much used in the kitchen, both for flavouring and as vegetables, that it would be out of place to omit mention of the uses to which they can be put. Many persons prefer the shallot to the onion, the flavour being more delicate, and having a peculiar character liked by many. In many gardens it is not looked upon with much favour as a vegetable, but the shallot will thrive when the onion fails. I do not advise the old method of culture, which was to plant in December and harvest in June, for much better results are obtained from later planting at a time when the plants can make progress. The best plan is to plant in March and harvest when the bulbs are ready, which will be in August. Ripen thoroughly before housing, and then place in a cool, dry store. There are some good varieties, the Sutton Giant being much better than the old form. At planting, place the roots in rows in well manured land, sufficiently deep to render each bulb firm, and at a distance of twelve inches between the rows and six inches in the row. The plants like rich food, and liquid supplies during growth will give fine bulbs. Garlic is largely used for flavouring purposes in large establishments, and needs much the same treatment as the shallot. There is a large Russian variety well worth growing, and in many gardens this plant is grown in the open all the year, being transplanted in the spring; but $I$ think that the produce is more useful if dried in the same way as shallots and stored. 


\section{Potatoes}

The importance of the potato in the vegetable kingdom cannot be overlooked. It is in daily use in most households all the year round, and is valuable in many other forms for commercial purposes. As a food it is more common than other vegetables, as it may be had good the whole year through with a little care in culture. A note on its value as a common vegetable would not be complete without referring to its seasons, culture, and other details. When forced, the new tubers are a delicacy, and, though my note does not go into details about forcing, I would add that much may be done to get an early supply by timely shelter. The potato does not always get fairplay; in certain soils it is not nearly as good as in others, and in some the crop is not nearly as large as in others, though frequently' the failure is attributed to the seed or the variety, and not to the cultivation. Though a rough-and-ready method will grow potatoes, the plant well repays the best culture. Only recently I saw two lots of potatoes in the same kind of soil, and of the same variety, one lot planted early in the season, the other late. What was the result ? The earlier planting, owing to the heat and drought, was quite double the weight of crop of the later planting, both being on a light soil. This shows how seasons affect crops. This year (I90I) I have heard many complain of poor crops in light land or on gravelly soil, and on asking when the planting was done have been told; " $O$, late in April or early in May: the plants were crippled at the start." I have this year noticed a lot of old seed tubers in the soil not decayed in the least. This shows the state of the soil early in the season. Of late years great strides have been made with the potato, and we have no lack of shapely tubers. The raiser of new varieties needs much patience, though in the end he may be 
rewarded by a good thing, but even then it takes years to work up stock. Still I am proud of such seedlings as Syon House Prolific, a good late variety, the Syon Main Crop, a mid-season variety, and English Beauty, a very early tuber. The last was the result of crossing Myatt's Ashleaf, a noted kind for early work, with the American, Beauty of Hebron. The Messrs. Sutton have of late years raised some beautiful tubers, and such are a great boon to our gardens. At the same time the field potato has received its fair share of attention. There are some notable cropping varieties, and if given fair culture few crops are more profitable. Our good old friend $\mathrm{Mr}$. Fenn, who did so much for the potato many years ago, should not be forgotten. Many will still remember his good work and the splendid crops obtained from his new varieties, like the Magnum Bonum-which is still a favourite, though later introductions have partially ousted it.

Early Potatoes.-Many persons can grow early potatoes who have not space for the mid-season or later kinds, and many place earliness before every other point. But flavour should be considered as the first point. The same flavour does not suit all. For instance, the Ashleaf varieties have a peculiar flavour of their own, a close firm character, whereas many persons prefer a loose flowery potato, so that in selecting early kinds this should be borne in mind. In many of the recent introductions the old Ashleaf quality is in a great measure retained, but the other parents have given tubers more flowery, the combination being most valuable. The tubers sent from abroad bear no comparison with our own early kinds as regards flavour. They are usually of a close or waxy nature, though this does not apply to some of the Jersey tubers, some of which are excellent. These latter are a great 
:; ; ; ; , ; , ;

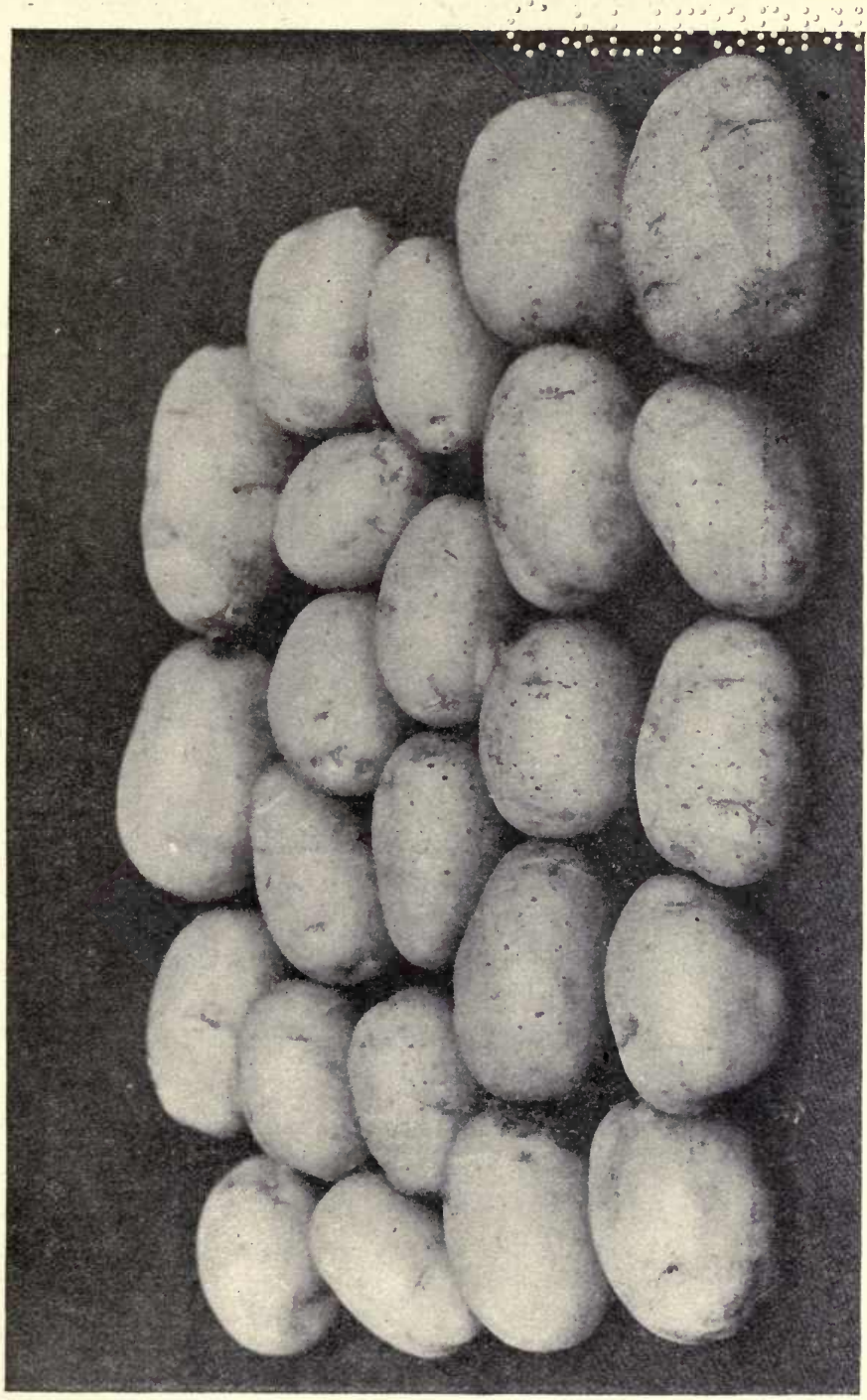

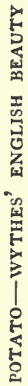



boon, coming in, as they do, just as our old tubers are fast losing quality through growing out badly. The potato is not a hardy plant, and, though it will stand a considerable amount of heat, will not stand frost. The latter greatly hinders early planting, and in our variable climate the growths are not safe from spring frosts till May is well advanced. For years, when I lived in the Midlands in a country district, I adopted a simple method to get an early supply, and it may not be out of place to describe it. We had plenty of fresh leaves every autumn, and these were gathered and placed in a huge heap till early in the year, when they were turned several times, and, if at all dry, well moistened to make them heat all through. They were then placed in position in front of some large conifers that gave effective shelter from the north, but allowed full exposure to the south. The bed when made was trodden as hard as possible, or beaten with a rammer as each layer of leaves was placed in position, and at the finish the bed was from four to five feet in thickness, and as wide as possible, for thus more warmth was retained. All round the sides of the bed was placed a liberal quantity of long, fresh litter. This kept in the warmth, and also kept the leaves from blowing about. At the middle of February, or a little later, the tubers were prepared for the bed. These were placed in boxes to make sprouts, and at the planting each tuber had the shoots or eyes rubbed out to one or two-the strongest. We usually placed the tubers in frames or fruit houses to give a start, but they are better not started at all than allowed to get too forward. I omitted to say that, when the bed was made up, nine to twelve inches of good soil was placed on the surface, and we usually saved the soil from an old cucumber bed, which was fairly rich, for this purpose. This, being made firm, got nicely warmed by the time the sets were planted early in March. The 
critical period is just when the tops are pushing through the soil early in April, and to protect at that season we have used straw-thatched hurdles, these being placed on stakes supported with cross pieces of wood. I think that dry bracken is the best protection, but it must be cut green early in the autumn; for, if allowed to ripen, its protecting powers are reduced, it is brittle and breaks very quickly. Cut green, it is light and warm, and readily placed in position or removed.

Potatoes forwarded thus will be ready for use in May, and are not so small as the first earlies in the open. The labour of making up the bed is not lost. As soon as the crop is cleared the space does grandly for such crops as marrows, cucumbers, capsicums, or any crop grown in a similar way, and the bed at the end of the year is of great value for potting-soil or as a dressing for heavy land. A south border should be selected for an early crop in the open, and if possible a light friable soil well manured in the previous autumn. The sets should have been well matured, and two feet between the rows is a fair distance, nine inches being allowed between the sets. We draw rather deep drills, and these, when covering with soil, are not quite filled up, so that in severe weather it is an easy matter to place a little long litter over the sets, removing it when it is warm or bright. A fair distance between the sets is nine inches, but a great deal depends upon the variety. The Ashleaf does well at this distance, but strong growers benefit by more space. As regards variety there is no lack. Such kinds as Ringleader, May Queen, and Ninetyfold are very fine for early borders. The last is superb, and has a stronger haulm than the Ashleaf. To these may be added English Beauty, Early Puritan, when large quantities are required, and Sharpe's Victor for small borders. This has a very dwarf top, and is one of the earliest. For field 
or market garden culture, Snowdrop is one of the best. To this may be added Harbinger and Duke of York.

Mid Season Varieties.-Some of the best flavoured tubers are in this section, and what makes them more useful is that, being planted when the soil is in a-warmer state, the growth is more rapid than with the other classes. April is a good time to plant both these and the

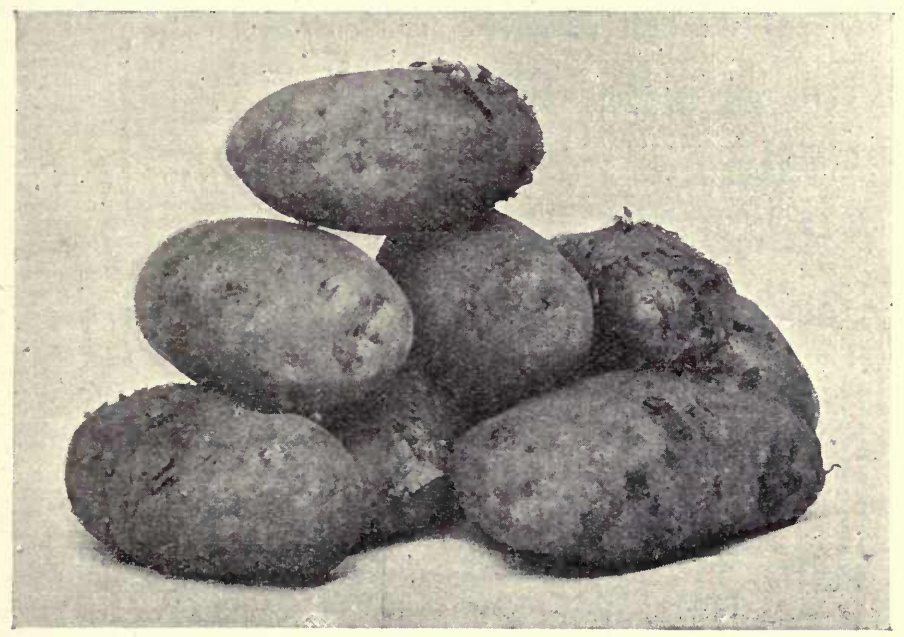

POTATO-SUTTON'S SUPREME.

late crops, early in the month in the southern part of the country, and later on in the north. As far as space is concerned, a great deal depends upon the variety, and a kind that grows tall needs more space. In planting it is advisable to give land that has not carried a similar crop for some time. This cannot always be done. When possible, prepare the soil some time in advance of planting, avoiding rank animal manures, as 
these in some seasons cause scab and other disease. I have seen much better results in old garden land by omitting animal manures for a season, giving a thorough dressing of lime, and using some approved artificial food. The land often lacks lime, and such aids as burnt refuse or road scrapings from limestone roads are very beneficial. As regards varieties, I place Windsor Castle in the front rank. It is one of the best flavoured main crop potatoes grown, is good in most soils, turns in early, and keeps well. Other kinds are the Snowball (Carter's), Sutton's Supreme, Satisfaction, and the Canon. There are many others, but those noted are among the cream of this section.

Late Varieties.-These need more care in selection, as the season they are required to supply dates from October or November to June of the following year. The mid-season varieties will give a supply till the New Year, and, if possible, this should be arranged, as then the late ones will fill in the other portion with less difficulty. Even late potatoes are not very palatable in June, but a great deal depends upon the way they are stored, on the variety, and on other details such as cooking and preparation. There can be no question whatever but that many late potatoes are ruined during the winter months by being kept too warm or allowed to grow out too much. Far better clamp the tubers in the open than store in a warm shed or cellar, for the latter soon affects the flavour of the tubers. Another point of importance is to have fresh seed whenever it can be procured. Though at the start it adds to the cost, it well repays at the finish by the greater weight of crop and the superior quality. No crop that shows disease badly should be retained for seed. It is as well to have a plot of land specially retained for seed purposes, if at a distance so much the better. 
For our late tubers we always have our seeds grown quite a hundred miles away. These are the Syon House Prolific, and we are the gainers by the very fine crops of tubers produced annually. The land soon sickens if the same thing is grown repeatedly. Another point is to give strong growers ample space; indeed three feet between the rows is scarcely sufficient for some, and half that distance should be allowed between the sets in the row.

I have briefly touched upon manures, and it must not be inferred that I am not in favour of ample food. The plant needs food to build up a mass of even-sized tubers, but much depends upon the soil. For late potatoes ample food is needed, but the tubers must not be placed on it. I prefer the food to be under, as the roots soon find it, and in dry seasons it is of great benefit to them as it supports at a time when the tubers are forming. I have named a few of the best varieties in the main crop section, and to these may be added Goldfinder, a white oval tuber of splendid quality. A floury tuber with shallow eyes, King of the Russets, is another very fine late variety, and the older Schoolmaster is difficult to beat as regards flavour and keeping properties. The Bruce and Sutton's Triumph are both good, and many persons like the Scottish Champion. For late spring supplies it is a great favourite in the north, and the newer Up-to-Date is a fine cropper and of good quality.

\section{Peas}

The green pea is an important vegetable in British gardens, and, like other vegetables, has received special attention during the last quarter of a century. Though I am not disposed to place too much importance upon the great improvement made as regards earliness, there can be no question whatever but that we have a 
much better quality, size, and dwarfness of haulm. There is now no need to grow the small, white, early pea so much seen in our gardens many years ago, or what may be termed field peas, that so soon got old and flavourless. On the other hand there is a difficulty in most gardens in having green peas at the end of May, and such peas are worth special culture. Some which have a distinct marrow flavour and are good croppers, are equally hardy with the old Kentish Invicta or Sangster's No. I. I shall not recommend any varieties having a thin, weak haulm, even though such peas may be a few days earlier than the stronger growers; for though earliness, especially in large market gardens, means a great difference in the price received for the produce, I am sure that the balance would be on the right side if a better quality pea was grown, and a variety specially selected for the purpose named. I am not an admirer of the very small dwarf peas from six inches high. I do not think that these very dwarf growers are the best if quantities are required, though of course a few rows for first supplies, and for frame culture, are valuable, but for general use such kinds as Chelsea Gem, the Sutton Seedling, Marrowful, and Bountiful are splendid types for earliest supplies in the open. To these may be added Carter's Early Morn and Daisy, a very fine selection, both as regards crop and flavour, with earliness combined. Of course there are other varieties equally good, but space does not allow me to give a long list of names, and those I note are types of the best kind for early work; and the pea being such a favourite vegetable, I will endeavour to give as long a supply as possible. To do this it will be necessary to divide the different kinds into four classes, early, second early, mid-season, and late; though I regret to say that in many gardens it is a difficult matter to grow late peas. This often happens in a light gravelly soil, and in the 


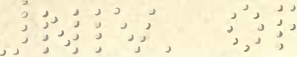

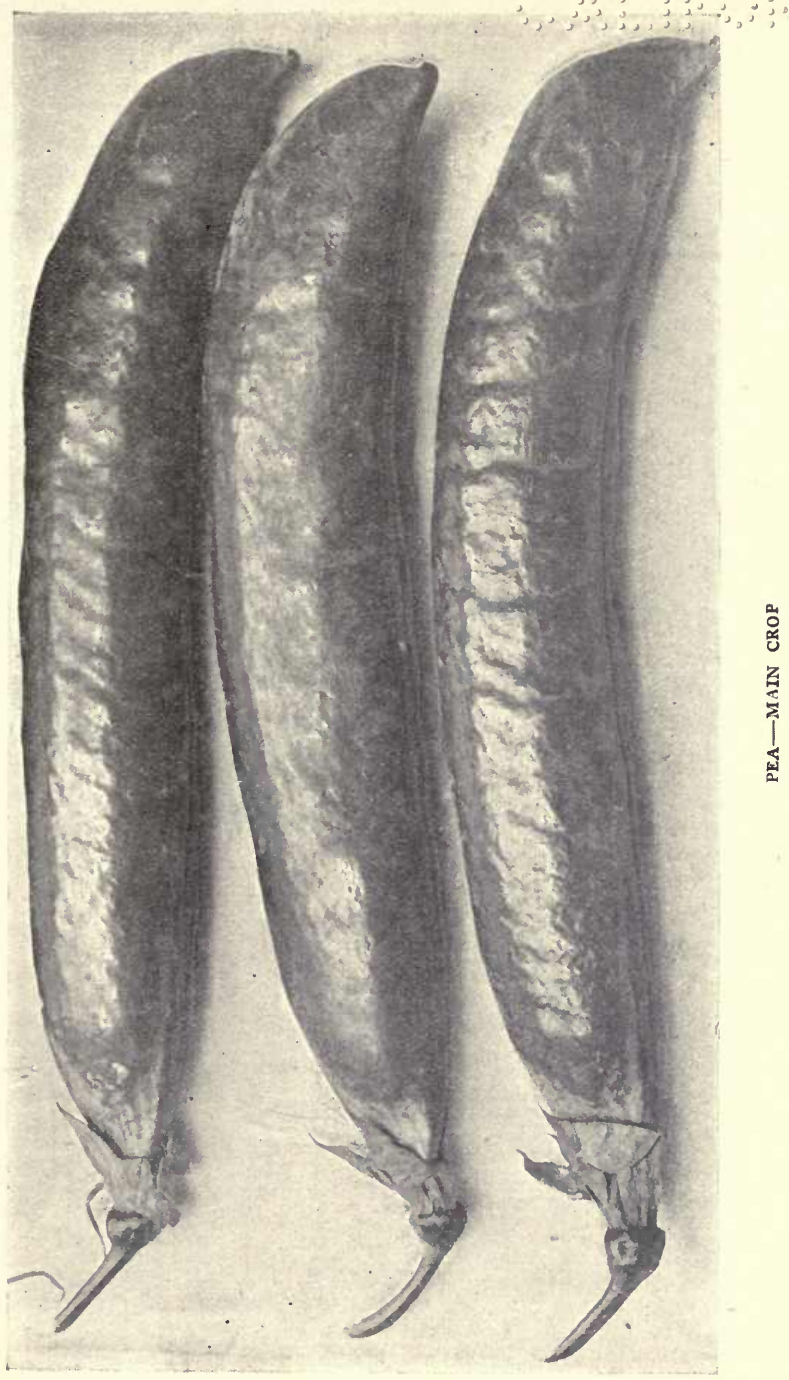



warmer parts of the kingdom. As far as my own experience goes, here in Middlesex, we are fortunate in our early peas, but not in getting a good late supply; whereas the reverse occurs at Alnwick Castle, in Northumberland. In the north, I have splendid late peas well into November in a mild autumn, and there are some splendid late kinds, a few of which I will note. I am not able to devote space to forcing, but for this purpose the earlier peas I have named are very suitable either in pots or frames. I give an illustration of the Daisy pea-a grand forcing variety. I may also refer to the Syon House Main Crop, a cross between Duke of Albany and 'Telephone.

Early Peas.-The earliest peas are always favourites, as they come in at a time when there is none too many choice vegetables. There is a great difference of opinion as to the advantage of sowing in autumn in a favoured quarter, say at the foot of a south wall. I am not in favour of the old practice, as, having given this work special attention, I find that the best results are obtained by sowing in November or early December, and then growing in a cold frame till planting out. I am aware that many of my readers will term this forcing, and in a measure it is, but it is very slow work, and many fruits, flowers, and vegetables, are hastened by a little timely shelter at the start. I find that peas not given heat of any kind are much more reliable than those grown in a shorter time. I have never seen the plants suffer if sown as advised; but, let me add, always sow new seed (the last season's crop); this is more vigorous than old seed. We find four or five inch pots best for the seed sown in cold frames, and we do not crowd the seed. If it should be necessary to sow thickly, the seedlings should be thinned to give the plants room. Nine to twelve seeds in a pot are ample; thin to six plants evenly distributed over the soil, the 
seedlings being given ample ventilation on all favourable occasions, and then planted out early in March in deep drills, the plants being made firm at the planting.

The reason that $I$ have not advised sowing in the open ground in the autumn is the uncertainty of the crop unless grown in the most favoured localities. Mice are very troublesome, and at times difficult to get rid of ; and birds are troublesome, as also are other pests, such as slugs and snails. These have a great liking for the tender pea in the winter, and the plant is much weakened by their ravages. Another evil is that though for a certain time the plants do well, we often get a succession of frosts one after another, and then cold east winds, the latter quite crippling any growth that may have escaped injury. That is why I advise frame culture in the early stages of growth, and though I have recommended pot culture there are other ways equally good. I have used turf, that is, a long strip three to four inches wide and three deep, but one must be sure that there is no wire worm or grub in the turf. The latter is placed in the frames, the grass side downwards, and then the seed is sown in lines in the middle of the turf and covered with light, rich soil. Many make a depression in the turf before sowing, and if this is done the seeds should not be crowded but placed evenly; indeed the best plan is to press each seed well into the soil at equal distances and then cover with more soil. I have also seen shallow wooden boxes used, and the plants slid out at one end. At the planting, in fact, any method that can be adopted will be worth trying if a good plant is secured. In the north, I have seen good results follow sowing under hand glasses, and also on the north side of land well ridged up, the snow protecting the plant at a trying period of its existence. As this note will show, outdoor sowings in autumn under the best conditions are precarious, and it is not well to sow large quantities. 
We now come to the first sowing in the open, say in February, if the land is not frost-bound or too wet. It will have been advisable roughly to ridge up land in which it is intended to sow the first crop in the open. If this is done in the autumn the soil is so much more workable, and sowing can be made earlier, than in land in a wet condition. For this crop I do not think the land needs the same quantities of food as for later crops, indeed, in wet land there is a danger of marrow peas failing to germinate unless the soil is friable, and heavy bodies of wet manure add to the difficulty at the season named. I have found that, in the case of dwarf varieties, we get the best results, if the soil is poor, by taking out a few inches deep and replacing with old hotbed, decayed leaf soil, or burnt refuse, so that there may be some good soil for the roots to push out into and root freely. Early in the season, the wrinkled sorts may be sown a little thicker than others, as the best peas are not so robust as the round. On the other hand, at later sowings the large growers, I do not mean tall but strong haulm kinds, need more room. I have seen Peas sown like Mustard and Cress, but it stands to reason that such crops cannot develop properly. I have named a few of the leading early kinds; to these may be addcd Early Giant, a splendid three to four feet variety, probably the finest pea we have for March sowing in light, warm soil, and remarkably early. Much the same remarks apply to May Queen, a slightly dwarfer variety, and of splendid flavour. I have before referred to Bountiful, and this variety can be sown where others fail. This is a blue-seeded variety, a very free bearer, and, like most of the varieties I have described above, a continuous cropper. This latter point should not be overlooked in garden peas, as any variety that is over in a few days is not valuable. For field culture, the crop maturing quickly at one time is a gain, but not so 
in the garden. The advent of the American Wonder Pea many years ago was a great point as regards earliness, and it was of better quality than our small white round peas, but since the time of its introduction great strides have been made. We have had Exonian, William the First, and many others, one of the best being Chelsea Gem. All these are vastly superior to American Wonder. One of our best peas is Gradus. This is a three feet variety, and is a splendidly flavoured marrow. The late Mr. Thomas Laxton, who raised this pea, certainly gave us one of the grandest peas the last century produced. Though a few days later than the very dwarf kinds, it may be had as early if the points are pinched out when the plants are about two feet high; and I do not know of any variety better than Gradus to sow in March to make a succession to the first earlies in the open. The Daisy is also specially good for the same purpose, as it is a very beautiful pea, and bears a large pod in comparison to its dwarf growth.

Second Early Peas.-In describing the earlier kinds I have also included a few that are excellent for growing as second earlies, notably Gradus, Daisy, and Bountiful ; the latter, where quantities are required, being especially good. The culture is much the same as for early kinds, except that the soil may be richer, as there is less fear of the seed decaying in the soil. Even at the early period of the year, or for seed sown in April, I would advise either shallow trenches, or rather deep drills, with a liberal amount of well-decayed manure in the bottom. In sowing in drills, avoid the old method of drawing drills, so that the drill is triangular-that is, pointed at the bottom. In such a drill the seeds roll down one on the other, and cannot get fairplay; it is far better for the drill to have a flat base, and the seeds to be at even distances. We see the great advance 


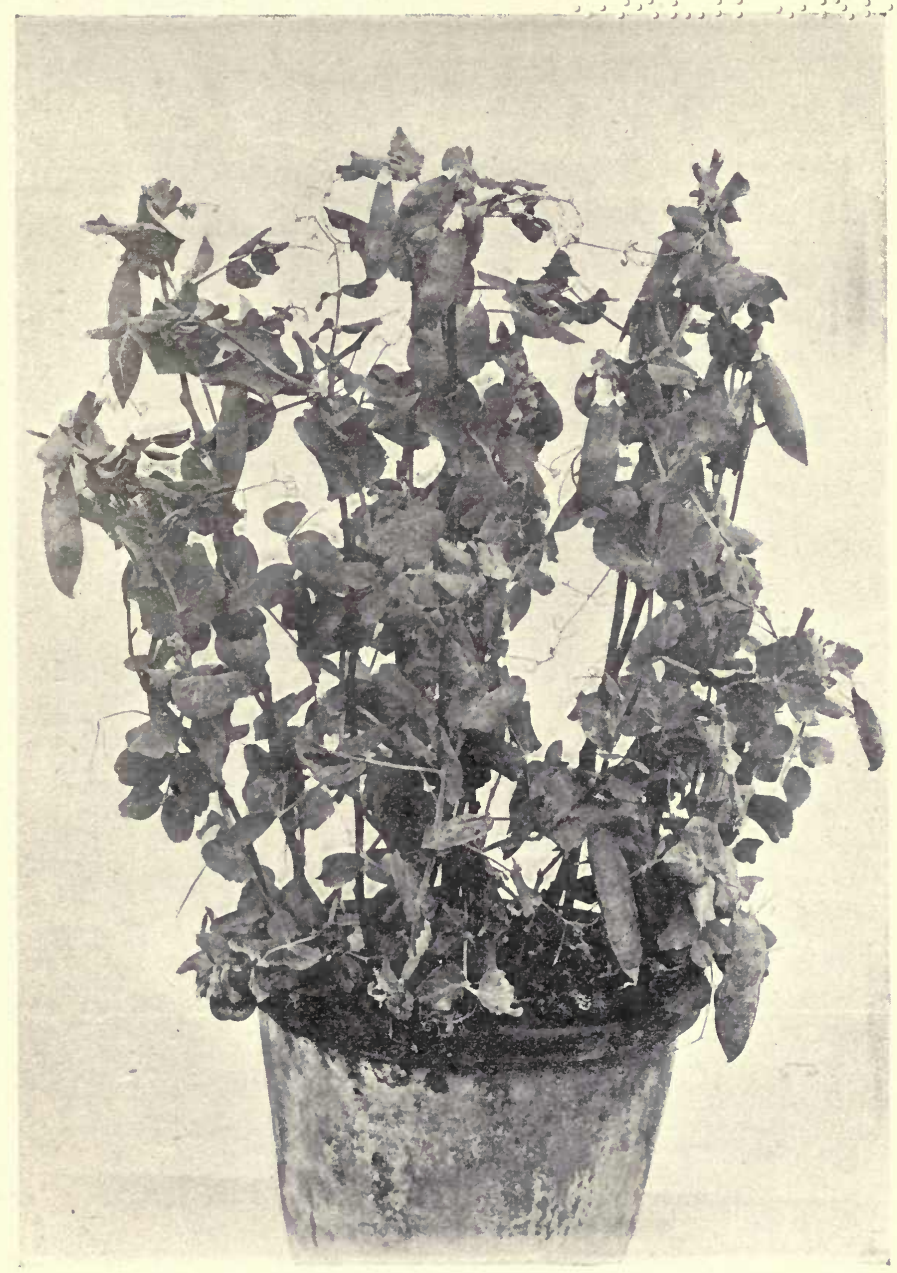

PEA-CARTER'S DIASY 

that has been made in the sweet peas, and much of this success is owing to improved culture, ample space, and good food at the root.

To get a succession of peas, it is well to sow every three weeks, and even then a few of the main crop varieties soon catch up the earlier sowing. As regards distance between the rows, this must be governed by the height of the plant; in any case it is best to give as much space as possible, and there need be no loss of ground, as small crops may be grown between. In our own case, we give our first earlies, sown in the open, three feet, and between each pair of rows we plant a row of lettuce. Though most of the peas may be three feet, we pinch or top at two feet, and, as we stake heavily with yew or laurel branches to ward off cold winds on the side most affected, the shelter given to the peas also assists the lettuce. Another plan is to sow early spinach in boxes, and transplant between the peas; also early cauliflowers of the Early Forcing or Snowball type are suitable to plant, as advised for lettuce. In the second earlies there is a wide choice. Dr. Maclaren is still a good variety, a wrinkled marrow of great excellence. Majestic is a very fine pea among the newer kinds, a pure marrow with large pods; and Stratagem is certainly one of the best-flavoured marrows and one of the best croppers we have in this section. Telephone and Peerless Marrowful are very good in cropping and quality. - Duke of York and Duke of Albany are well known; both being equally good in the third division or main crop varieties. I only have one objection to the Duke of Albany. The plant, though it crops well, does not bear a long crop, the pods being produced in a short time; still it holds its own on the exhibition table. Other good kinds are plentiful, but enough are described to show season and mode of culture. 
Main Crop Peas.-These in many gardens are often the last crops, not because the cultivator does not require later ones, but because the soil, situation, and weather are not favourable for later supplies. As some of the best second earlies do well for this crop, I will not go over the same ground again, but merely note that the main crop may be lengthened by preparing the soil specially for the purpose. Much may be done in unsuitable soil by growing in trenches, and in this section will be found the best of the marrow peas. Such varieties as the Eureka (a splendid marrow), the Magnum Bonum, Marrowful, Satisfaction, Best of All, Windsor Castle and Reading Giant give a list that contains the cream of the July and August peas. To these should be added Veitch's Perfection for good loamy soil, Main Crop, and the splendid Autocrat. The latter rarely fails in any soil or situation, and is equally good for later work. This with us in the north is one of our best late varieties. Another very fine main crop is Alderman, and the new E. Beckett promises grandly. To these may be added Culverwell Giant, Marrow and Omega.

Late Peas.-In this section are some splendid marrows. The old Ne Plus Ultra is still one of the best if a true stock can be secured, and such kinds as Carter's Michaelmas which may be termed a dwarf, British Queen, Emperor of the Marrows (a tall variety), Reading Giant, Sutton's Late Queen, Latest of All, and Continuity give a list from which a selection may be made. Some kinds do better in some places than others, and in poor soils I would advise the robust growers and the dwarf or three to four feet varieties. In soil where these fail I would adopt another plan, and that is, instead of sowing these late kinds, to sow the first earlies for the last supply. Such kinds as Chelsea Gem, May Queen, Daisy, William the First, and others of a similar nature will do when others fail, but the land 
must be good, ample moisture being given at the start if the weather is hot and dry. It is a good plan to soak the seeds for a few hours before sowing, to sow in deep drills, and to sow the tall varieties in trenches with a fair amount of decayed manure in the bottom of the trench; if the border can be partially shaded, so much the better when the plants are young, as they do not like too much hot sunshine. The dwarf kinds, that is, the earliest, are sometimes grown for late supplies; I have grown these on an eastern border, but a great deal depends upon the locality. In the north we find that the late crop does best in open quarters, so as to get full light and sun at the finishing season. To set the late blossom and to get best results, give ample room between the rows. In this country very few peas are cooked whole, as is the Edible Podded or Sugar Pea. They are of delicious flavour if gathered in a young state. Of course they need good culture, and should not be grown in any out-of-the-way corner and then condemned as useless. Doubtless the Editor will note the value of these varieties as a change from our ordinary kinds, as they are most delicious when well cooked. There are not many varieties, and though called the Sugar Pea, I am not sure that the name is the best, though the pods certainly are sweet. The sweetness is not objectionable if the pods are gathered when not too much advanced. The seeds or peas should not be allowed to harden. On the Continent these find great favour, and one variety, the Delicatesse or Petit Pois, is well worth growing in all gardens where variety and flavour in vegetables are valued. The last-named is a great cropper, grows about three feet high, and is best grown with sticks. Another variety, the Giant Edible Podded Pea, is larger than Delicatesse and a taller grower, being five feet. This is a better variety in heavy land than the former, and crops a long time. 
They all like ample moisture, and do not thrive well in poor dry soil, the pods in such soil being quickly infested with thrips.

\section{BEANS}

The Broad Bean comes first on the list, being hardier than the Dwarf or Runner, but it is not so much grown as the two last-named, as the produce soon gets old, and many persons object to it on that account. I fear it is not generally known that the rough, peculiar flavour may be got rid of if the beans, when of any size, are skinned. Even when the seeds blacken at the outer portion, the flavour is much improved by skinning. Another point is that it is not necessary to allow the plants to mature the pods; it would be far better if the crop were gathered earlier, as by so doing better flavour would be secured, and the plants would benefit. I briefly note the above, as doubtless the Editor will deal fully with the subject as regards cooking. My note concerns flavour.

The culture for an early supply is most simple, if the ground is not too wet or heavy. Seed sown in November will give a fair return, and, as regards hardiness, after several years' trials, there is not much difference between the Early Long-pod section and the older Mazagan. The last-named is remarkably hardy, and, though small, for a private garden this latter point should not tell against it. Sown alongside of the earliest of the Long-pod section, it is the earlier of the two. I would not advise the Mazagan for field culture where size is an important point, but in the kitchen of course only a limited quantity is needed for a first supply. The Early Long-pod section sown in February will give a succession until the autumn-sown come in. There are several difficulties in growing beans, and 
the worst are caused by the jackdaws and rooks which dig them out of the soil. Mice, too, in the winter months are fond of them, and worms and slugs eat the fleshy root portion; so that, unless earliness is important, I would advise sowing in February. Again, in March and April the larger Long-pods and the Sevilles are all suitable. The Green Giant broad beans are a newer introduction, and notable for their green colour and delicate flavour. This variety crops as freely

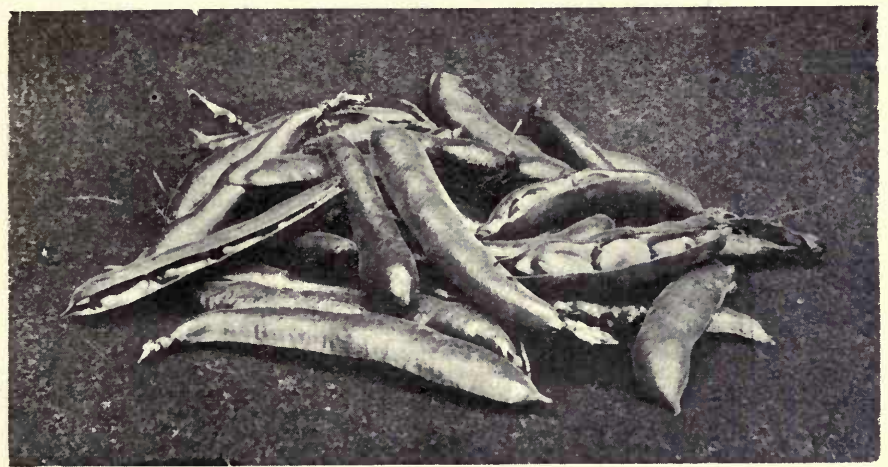

BEAN-GREEN LONGPOD.

as the white-seeded. For latest crops the seed should be sown in a holding soil, and for that purpose the Broad Windsor types are the most suitable. These surpass the others in quality, and are best sown so that the pods come in succession. There are several good Windsor types, the Old Broad variety, the Improved Windsor, Taylor's Windsor, and Green Windsor. There is another type of bean that should not be overlooked, the small cluster known as Royal Cluster, a very productive variety with branching habits, but not 
the best for all soils; it is valuable for shallow soils and early supplies. Another very good small early bean is Beck's Dwarf Green Gem, which is very prolific and hardy.

\section{Dwarf Beans}

This is a popular summer vegetable, and most valuable for supplies from June to October. The best use is not always made of the dwarf bean. In some gardens one or two sowings suffice, whereas if the same or very little more seed were spread over half-adozen sowings made at different dates, the results would be better in every way. I am aware that, to do this vegetable justice, it should get rich soil and ample moisture during growth, as lack of moisture is the forerunner of red spider, and the plants fail to set the flowers. As regards soils and situation, the best position is an open one, selecting a light loamy soil, not too clayey or wet; for the first crop a warm border under a south wall is the best. Much can be done to forward an early crop by sowing under glass and then planting out, but I will not dwell upon this work. No matter what the part of the country, it should be borne in mind that the dwarf bean is by no means hardy, and that there must be sufficient warmth in the soil to germinate the seed. It is not a British plant, and very early sowing, especially in heavy soils, will often fail. The proper season varies. In the south I have sown early in April, but the middle of the month is generally full early, and the end in later seasons or on heavy soils. On the other hand, it well repays the cultivator to make the soil suitable for the first sowing, as it is not thrown away for other things which require a light soil. It is an easy matter to cover the seed with any light soil after sowing, and in cold, wet weather early in the spring, land well drained should be selected. 


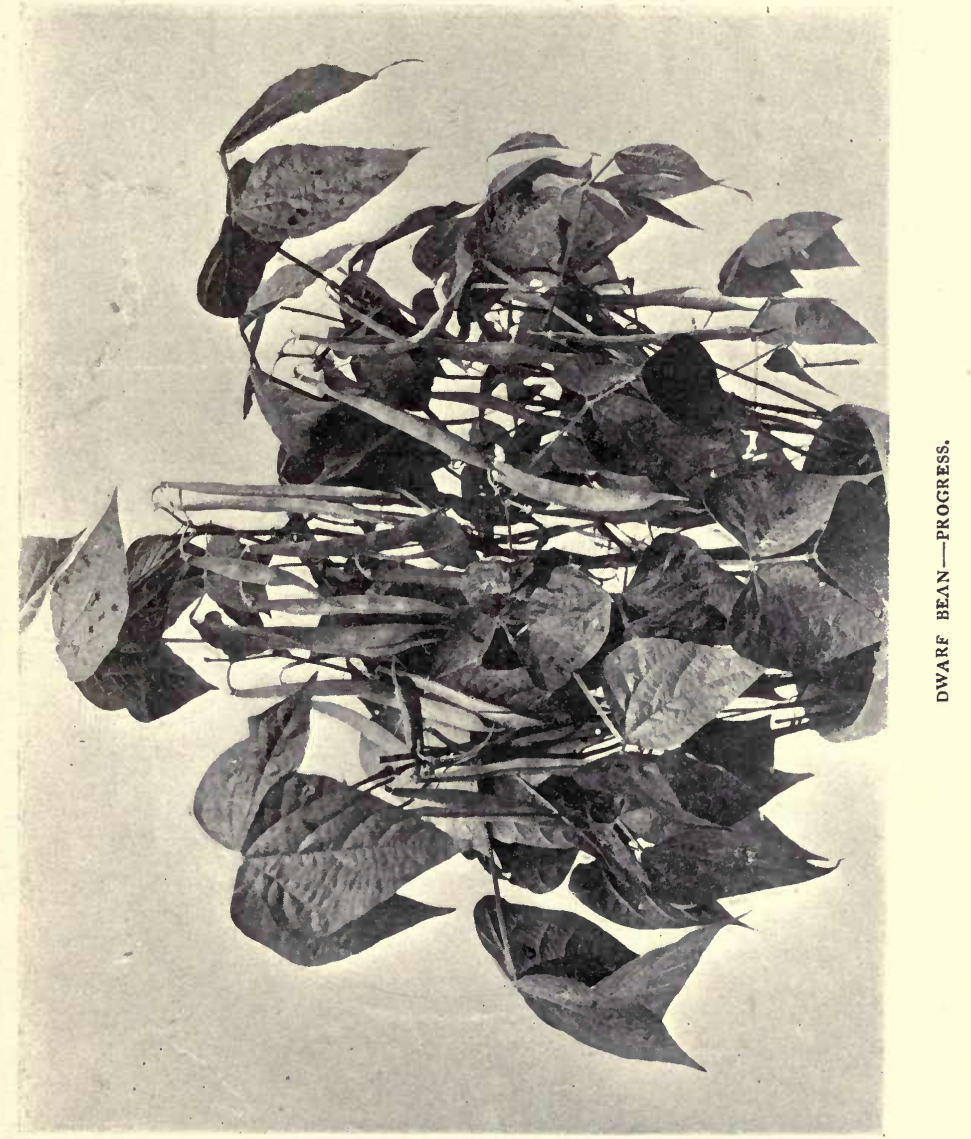



If the seed is sown early in April, the crop will give an early July supply, another sowing made, say, four weeks later will give a succession, and another sowing in June will give a later supply. A still later sowing may be made for an early autumn supply, and from May till July there will be no doubts as to the seed germinating, so that ample room should be given the seed; and though it may be well to sow more thickly than the plants can remain, it is an easy matter to thin the seedlings when it is seen which are the strongest.

$V$ arieties and Culture.-For early crops the small-podded varieties are best, being earlier; one of the earliest beans to show blossom and mature being Syon House, a good flavoured variety. Ne Plus Ultra also is very good, and produces freely. This bears a small, thin, green pod, has dwarf habits, and is a great cropper. For later cropping there are some beautiful types, such as Progress (see illustration), Triumph, Perfection, Long Sword, and many others. Indeed, it is difficult to give a selection, there are so many good kinds. Some in different localities have different names, and I note a few to show the best type for summer use. For May and June sowing, the larger Canadian Wonder is a very fine variety. This gives larger pods than any of the former, but I should add that no matter what the variety, the crop should be gathered regularly, and none allowed to get old, as the plant soon fails to crop if allowed to ripen or carry old pods. I have touched upon the needs of the plant as regards food and moisture. Few plants will absorb more food; they delight in a rich root-run of good decayed manure. This placed liberally in the bottom of the trench or drill will do much good in hot, dry summers, and if the plants are given liquid manure frequently, so much the better. They delight in overhead waterings in the evening after a hot summer day. This will do more good to keep them free of red spider than 
anything else, and daily or every other day gatherings will keep the plants healthy. In this country we allow many of our vegetables to get much too old before they are gathered. On the Continent the Dwarf or French Bean, as it is called, is used in a small state, often whole, with the result that the pods are greener and more tender, and have a beautiful flavour. Doubtless the Editor will touch upon the value of pods cooked thus in preference to our dry, sliced older beans with the seeds half-ripened and the pods stringy. This"also applies to the Runner, and indeed to many vegetables. There are some delicious butter beans in the Dwarf section, which are well worth growing and cooking whole. The Golden Beans are noted for their good flavour. Another type is the small Haricot Bean, a very good vegetable when cooked whole.

\section{Runner Beans}

Owing to the introduction of the Climbing French Bean there are two distinct runners. I will take the new ones first. These are mostly about six feet high, and the pods more like those of the dwarf than of a runner, except that they are all large, long, and slender. These new kinds are a great gain, as they continue in bearing a longer time than the dwarf, and the quality is excellent. The culture is the same, except that the plants should have at least six feet between the rows. More room is better; indeed, the best way to grow runner beans of any kind is to give a much wider space, and to plant between the rows with low-growing vegetable crops. The new runners have this in their favour, that they can be sown sooner than the larger fleshy scarlet runner. This is a gain, and they also turn in a fortnight or three weeks before the older variety. Another point is, that they are more marketable, and are better shaped, and the 
flavour is superior if well grown. Like all others, they need much moisture during growth, and ample room from plant to plant. The best way is to place the seed in drills or trenches at six inches apart, a double row in each trench being best if plenty of space can be allowed. By having trenches it is an easier matter to supply moisture. The following are excellent-Earliest of All, Excelsior, Epicure, Princess of Wales, Tender and True, and Veitch's Climbing. The last-named, though a little smaller than others, is earlier, which is a great gain. In 1900, the Messrs Carter of High Holborn sent out a remarkably early Climbing French Bean known as Ten Weeks, a decided gain both as regards earliness, crop, and productiveness. This, like the others named, should be gathered young.

The ordinary Scarlet Runner is grown so simply that my note concerning it will be brief. Much the same conditions of culture as advised for dwarfs are applicable, except that scarlet runners are sown later. It is not safe to sow till the middle of May in cold soils, as should they come through the soil freely the plants will suffer badly in cold weather. They should be covered at night for a time. Sown later there is no trouble, and, like the new climber, the plants are best sown in deep drills or trenches, and grown thinly. I need not give a long list of varieties, such kinds as Chelsea Giant, White Mammoth, Scarlet Masterpiece, Mammoth White, Best of All, Abundance, and the older Champion Runner and Painted Lady being all good. A much better crop may be secured by making an early sowing in May and one a month later, by which means a long season is secured. In market gardens the runner bean is not staked, but grown in rows like the Dwarfs. However, they do much better if given supports. 


\section{HISTORY AND COOKERY OF VEGETABLES}

BY THE EDITOR

\section{The Cabbage Family}

The name Cabbage is derived from the Latin Caulis Capitatus (caulis, a stem, caput, a head), and the words Kohl, Cauliflower and Kale show of course a common origin from the same root-word as caulis itself.

Several varieties of Cabbage seem to have been cultivated by the Greeks and Romans: Selinoides or Parsley-Leaved Kale, Corambe,'Calabrian Kale and so on. The value of this race of plants in providing a supply of winter food was early appreciated; and the need which cabbages have for rich deeply-dug soil was also an early discovery. Pliny speaks of nitre and seaweed as among the manures commonly applied. The Greeks and Romans ate cabbage both as a boiled vegetable, and raw, as a salad. Eaten in the raw state, cabbage leaves were supposed to ward off drunkenness and post-prandial headache, and were consequently in great request in the later days of the Empire.

The cabbage is a native plant of Britain, occurring wild in all parts. It has been here cultivated since the earliest times, and was a favourite vegetable of the Saxons, who derived their name for the month of February from the fact that sprouts began then to be ready for cutting.

Parkinson speaks of certain varieties of cabbage as being cultivated for their decorative value: "Many of them being of no use with us for the table, but for delight to behold the wonderful variety of the works of God herein." 
Gerard describes a number of varieties of cabbage -swollen Colewort, double Colewort, Rapecole and others; and Johnson in 1633 speaks of "the great ordinary cabbage, known everywhere, and commonly eaten all over the kingdom."

Pliny's "Corinthian Turnip," of which " the root is all but out of the ground; indeed this is the only kind that in growing, shoots upwards, and not as the others do, downwards into the ground," was probably our Kohlrabi, which was introduced into England in the sixteenth century.

The Cauliflower, in which the flower stems and abortive flowers have been artificially developed, was introduced into this country, probably from Italy, by way of Holland, in the sixteenth century, but for a long time it was an expensive luxury. Parkinson refers to it as a rare vegetable, and at the beginning of the seventeenth century cauliflowers seem to have cost about eighteenpence apiece. Gerard refers to the "coleflourey" as the best of all the kales, as indeed it is. From the seventeenth century onwards, it has steadily gained in popularity and extension of cultivation.

The Broccoli is a close ally to the cauliflower. It originated in Italy, as its name implies, and seems to have been recognised as a distinct garden variety in England at about the end of the seventeenth century.

\section{To boil Cabbage}

In boiling any members of the cabbage family, great care should be taken to serve them at the right moment, as a very short lack or excess of time spent in boiling water quite spoils them. They should first have the solid outside leaves removed, and then be placed in cold salt water for a time and carefully examined for snails, caterpillars, and other creatures. They should next be placed in a large quantity of boiling salted water containing 
no soda, and boiled till just tender. The lid of the pan must be kept off during the whole time of cooking, and the scum which rises to the surface of the water should be removed as it collects. Brussels sprouts take about fifteen minutes, whilst broccoli, cabbage, and cauliflowers take from fifteen to twenty-five minutes according to size. Broccoli and cauliflowers should be placed in the saucepan flower downward, and a deep cross be cut on the stumps. Cabbages should be cut into two or four sections by vertical incisions. All forms of cabbage may advantageously be steamed instead of boiled. When boiled they require thorough draining in a colander. Brussels sprouts, savoys, or red cabbage may be shredded and boiled in a minimum of good stock, with butter (an ounce to a pound), and a little pepper, salt, and vinegar.

\section{Cabbage and Cheese}

Cauliflower, broccoli, Brussels sprouts, cabbage, or indeed, almost any vegetable may be used in pleasant combinations with Cheddar, Parmesan, or other cheese. The vegetables must first be boiled in the usual manner, drained, and fried to a nice brown, though this latter proceeding may be dispensed with. "The vegetables should then be placed in a pie-dish, with (to each pound of vegetables) three ounces of butter, a large cupful of stock or brown sauce, half a saltspoonful of pepper and a saltspoonful of salt. Stir well together, grate cheese liberally over the whole, and bake in the oven for about twelve minutes.

Mrs W. G. Waters, in her very readable and very suggestive "Cook's Decameron," gives a valuable recipe for

\section{Cavoli fiori fritti :}

"Break up a broccoli or cauliflower into little bunches, blanch them, and put them on the fire, in a saucepan with 
good gravy, for a few minutes, then marinate them with lemon juice and salt, let them get cold, egg them over, and fry in butter."

Red cabbages may be used in many ways. In "Les Dons de Comus" (I758) is a recipe for

\section{Choux Rouges Comfits.}

Prenez des choux rouges et les faites blanchir une demi-heure. Empotez-les avec du vinaigre, une douzaine de clous de girofle, cinq ou six gousses d'ail et du sel.

Red cabbages, as everybody knows, may also be used to make an excellent pickle.

Mrs Roundell's recipe for

\section{Colcannon}

is about the best. Take equal quantities of cold cooked cabbage and potatoes. Rub them through a sieve and mix them well together. Add pepper and salt, a little butter, and a well beaten egg. Butter a small pudding basin, press the colcannon into it, and bake in a hot oven for from thirty to forty minutes. Turn out into a hot dish and serve. The mixture may be fried under a plate or dish instead of being baked in the oven.

Lady Harriet St Clair (who married the German Ambassador, Count Munster) gives in her "Dainty Dishes" a number of German recipes. Among others, she describes the preparation of

\section{Sauerkraut.}

"Choose firm white cabbage heads, remove the loose outer leaves, cut out the stalk and the coarser fibres at the back of the leaves. In Germany they have a particular sort of knife, more in the nature of a plane, with which they cut the cabbage in fine strips, but an ordinary large knife will answer the purpose as well. This 


\section{THE BOOK OF VEGETABLES}

must now be done, and to about thirty firm middlingsized heads you allow half a pound of salt. Mix the salt lightly with the cabbage, covering the bottom of a small oak barrel or cask with cabbage leaves, and pressing the cut cabbage and salt jointly into the cask, either with your hand, or, better still, a wooden pestle. When it is quite full, place another layer of cabbage leaves on the top, then a clean cloth, and after that the wooden cover, with stones laid on it to make it heavier. Keep it in a moderate temperature till it begins slightly to ferment, and then put it in a cold cellar. If it appears not to be juicy enough, boil salt and water together and pour it over the cabbage. It is usual to strew carraway seeds among the cabbage, and in many parts of Germany sour apples or unripe grapes, which are said to be a great improvement. It is usually made in October, and is ready to eat in February."

To dress Sauerkraut, it must be lightly pressed, and, if very sour, washed. It should then be placed in a welltinned saucepan with as much water as will cover it, an onion and a piece of lard or goose fat, and boiled slowly for from three to four hours. Mix a little flour and butter together, stir it up with the cabbage, take out the onion, pour a glass of wine over it, and let it stew slowly a little while longer. Some people add sugar and apples to it. The great art in cooking it is that it should not be greasy, and be neither too dry nor too liquid.

\section{SPINACH}

Spinach seems to have been known as a kitchen vegetable in the fourteenth century, though it does not appear to have been grown in English gardens before the sixteenth. It soon won high favour and Gerard said that "of all pot-herbs it maketh the greatest diversitie of meats and salads." Parkinson said that 
"Many English, that have learned it of the Dutch people, do stew it in a pot or pipkin without any moisture than its own. It is used likewise to be made into tarts and many other varieties of dishes, as gentlewomen and their cooks can better tell than myself."

In Turner's " Herbal," published in the sixteenth century, spinach is referred to as " a herb lately found, and not long in use," but it seems to have been known if not grown in England as early as the fourteenth century.

Worlidge in his "Systema Agriculturae" makes no mention of spinach, but Evelyn makes numerous references to it; and Gerard said that "of all pot-herbs it maketh the greatest diversities of meats and salads."

In Miller's "Gardeners' Dictionary," it is said that "perhaps the Spaniards had this plant from the Saracens; but by some it is considered to be indigenous to Spain, as many of the old botanists - such, for example, as Bock-call it Olus Hispanicum. Ruellius and others name it Atriplex Hispaniensis. It does not seem to have been known to the Greeks or Romans, and was probably introduced into Europe from Asia, as its name implies.

\section{Sterved Spinach}

Spinach having been washed in cold water and dried by swinging the leaves round in the air, may be stewed in the following way.

Place it in a pan of boiling water, whence remove it at the end of four minutes. Throw the spinach next into cold water and well dry it in the colander. Chop it up moderately finely, and place in a stewpan with salt, pepper and butter (half an ounce to the pound). Place over the fire and stir till the butter is melted. Add a little stock (a teacupful to the pound), and allow to simmer for ten minutes. Add a little lemon juice and 
serve. Spinach cooked in this way may be spread on toast and surmounted by poached eggs.

Spinach may be served whole by placing it, without water, in a vessel surrounded by boiling water, for about twenty minutes. Dry with a warm cloth and serve.

\section{BEETROOT}

Beet and spinach are allied plants, both belonging to the order of Chenopodiaceæ. Beet occurs wild as a native of Britain, as well as of many parts of Europe, Asia, and Africa. It was well known and cultivated by the Greeks and Romans, by whom a small number of garden varieties was recognised. Theophrastus, Aristotle and Pliny all wrote concerning the plant, and described its uses as food and medicine.

Alexander Necham, master of St Albans' Grammar School, and subsequently Abbot of Cirencester, published in the twelfth century a little book "De Naturis Rerum," in which he gives an account of the fruits, herbs and flowers then grown in English gardens. He refers to beetroot as being then in use, and the plant is also included in the list of vegetables enumerated in the survey, made in the ninth century, of the gardens of the monastery of St Gall.

Worlidge, speaking of beet, says : "This ordinary Plant is by several made use of ; it loves a fat and rich Soyl; it's usually sown in the Spring, and will come up several years in the same ground, and may be planted forth as Cabbages are."

The beet was first cultivated for the sake of its sugar at about the middle of the eighteenth century.

\section{To boil Beetroot}

The skin of beetroot must on no account be broken before cooking, or the colour and the sugar will escape. 
Place the roots in boiling water and boil for about an hour if the roots are young, or for about two hours otherwise. When the roots are cooked, place them in cold water and skin them. They may then be served hot with butter, pepper and salt, or with gravy, or they may be allowed to cool, and then sliced and served in vinegar.

Instead of being boiled, beetroot may be baked in the oven, and in many ways this method is to be preferred. The time required for baking is about the same as that required for boiling.

\section{Carrots}

Although it was a valued and carefully cultivated vegetable among the Greeks and Romans, and was described as such by Theophrastus, Pliny and Dioscorides, the carrot as an edible plant seems to have been introduced into England by the Flemings only in the sixteenth century. It very soon attained popularity, and Shakespeare makes Dame Quickly describe it as "a good root."

The garden carrot was originally derived from the wild species, Daucus Carota, which is a native of England. It belongs to the order of umbelliferous plants, and from its concave umbels of fruits has earned the popular name of Bird's-nest. According to Parkinson, ladies in his time were wont to use the graceful foliage of the carrot as a decoration for their hats, in the same way as modern ladies make use of feathers, or even-sad to say-of wings of birds. Its use as a vegetable in England dates from the sixteenth century, and Hanbury, in $177 \mathrm{I}$, wrote that the carrot " is now become, by good culture, a principal plant in the kitchen garden, and is one of the most useful, beneficial, and profitable esculents at our table." He refers to the then novel experiment, "the 
culture of carrots for cattle in fields; a thing that until of late years was never known, and which now amply shows itself profitable and beneficial in such places where land proper for the growth of carrots is found; and, where that happens, a good crop of carrots will be worth nine or ten pounds per acre."

\section{To boil Carrots}

Carrots are best eaten when very young, and they should then be cooked only just long enough to render them tender. This will take from half-an-hour to an hour.

\section{To bake Carrots}

The Flemish method of cooking small young carrots consists in first scraping them and boiling them till tender. Dry them, and fry them in butter for ten minutes. Add a sufficiency of stock just to immerse the carrots and allow to simmer till the stock is reduced by a half. Add a little pepper and salt, a little chopped parsley and a little cream. Place in a buttered pie-dish, cover with buttered paper and bake for ten minutes or a quarter of an hour.

To make

\section{Carrot Soup,}

take six medium sized carrots and two onions, slice them and place them in a stewpan together with two quarts of stock, a teaspoonful of salt and a quarter of a teaspoonful of pepper. Simmer for about two hours, strain (or leave unstrained) and serve. The vegetarian may use as stock the water in which haricot beans or lentils have been cooked.

Almost any vegetables may be used in the making of the excellent

\section{Minestra,}

or thick broths, so frequently served in Italy, yet so much more adapted to our colder climate. To make 
a minestra, one may take three sliced young turnips, a small sliced carrot, and a small sliced onion, a sliced stick of celery, or two sliced tomatoes, and fry them gently for five minutes in oil. Throw these fried vegetables, with quarter of a pound of rice, into three pints of good stock which is simmering, flavour with pepper and salt, and boil for one and a half hours. Serve with grated cheese (Parmesan or preferably dried Cheddar or Cheshire). Instead of the turnips, sliced cabbage may be employed, but this latter should not be fried, nor should it be added to the stock until forty minutes before the minestra is to be served.

\section{PaRsNips}

Parsnips have long been grown and valued, Pliny mentioning them as among the regular contents of Roman gardens. They seem to have been used at different times for the most curious ends-the making of bread and the making of a wine, said by an enthusiast to rival Malmsey and Canary.

Parsnips are included in the list of vegetables cultivated by the monks of St Gall in the ninth century, but there is no record of their cultivation in England until many centuries later, although the parsnip is a native plant. The ancients seem merely to have transplanted the wild parsnip into their gardens, and to have made no serious attempt by selection to find a variety free from the extreme pungency which marks the flavour of the wild plant. Worlidge speaks of the parsnip as " an excellent sweet root, and very pleasing to some people."

Parsnips, like beetroot, must not be cut before being cooked, or they will lose half their value. To boil them, having first scrubbed them with cold water, place them in a pan containing a minimum of boiling water. 
Boil for about eighty minutes, or until tender. Serve whole, with a simple sauce in a separate dish.

Parsnips may be cooked in any of the ways suggested for cooking salsify in "The Book of Asparagus."

\section{TURNIPS}

The turnip, in common with several other vegetables, seems to have been introduced into England by the Flemings in the sixteenth century, though its name (terrae napus) rather points to earlier Roman introduction. In any case, the Romans highly esteemed the vegetable both as food for man and as food for cattle. Cato and Pliny make frequent references to the turnip, and it is obvious that it was more valued than almost any other vegetable grown in Rome. Long after their introduction into this country, turnips were grown only in gardens and market plots for human consumption, and Gerard wrote: "The small turnip groweth by a village near London, called Hackney, in a sandy ground, and are brought to the Cross in Cheapside by the women of that village to be sold, and are the best I ever tasted. The bulbus or knobbed root, which is properly called rapum or turnip, and hath given the name to the plant, is many times eaten raw, especially by the poor people in Wales, but most commonly boiled." Worlidge, however, said in 1668 that turnips were being frequently grown on a large scale by farmers as food for their cattle. In the years I630 and 1693, owing to the failure of the corn crops, turnips were largely mixed with flour in the preparation of bread. Really, however, the food value of the turnip when eaten by mankind is not great.

As a moral symbol, the turnip has been considered to possess significance, and Canon Ellacombe quotes from Gwillim's Heraldry: "This is a wholesome root, and 
yieldeth great relief to the poor, and prospereth best in a hot sandy ground, and may signifie a person of good disposition, whose vertuous demeanour flourisheth most prosperously, even in that soil, where the searching heat of envy most aboundeth. This differeth much in nature from that whereof it is said, 'And that there should not be among you any root that bringeth forth gall and wormwood." "

The turnip grows wild in England, but whether our wild species be parent or degenerate descendant of the garden variety is uncertain.

\section{To boil Turnips}

Like most other vegetables, turnips should be cooked at a much earlier age than usual. They then should be boiled whole in slightly salted water, a process which takes about twenty-five minutes, and served entire with some simple butter sauce.

Older or less choice turnips, having been boiled till tender, may be drained in a colander and then mashed and beaten through the colander. They should then be placed with a little butter (an ounce to a pound), milk or cream, pepper and salt, in a stewpan, stirred over the fire for three to five minutes, and served.

Kohl Rabi may be cooked in the same way.

\section{Turnip Tops,}

cooked after the manner of minced spinach, afford a valuable winter dish. They take somewhat longer to cook than spinach. Cold turnip tops may be fried with potatoes in the same way as cold boiled cabbage.

\section{Jerusalem ArtichoKes}

The Jerusalem Artichoke is a native of North America, and was cultivated there by the Indians. Champlain, 
writing in 1603 , speaks of " roots which they cultivate, tasting like artichokes," and Gookin speaks of the Indians as putting slices of Jerusalem Artichokes into their soups.

The common title "Jerusalem" applied to this tuber has no reference to the place of that name, but is a corruption of the Italian word "girasola," meaning a sunflower. The plant was introduced into England at the beginning of the seventeenth century, but does not seem to have been adequately appreciated. Worlidge described it as " near of the nature of the potatoes, but not so good nor so wholesome; but may probably be propagated in great quantities and prove good food for swine. They are either planted off the roots or off seeds."

The ways in which artichokes may be used in the kitchen are many, so many, indeed, that it is difficult to select the most useful. To make

\section{Articboke Soup,}

take two pounds of Jerusalem artichokes, and, having peeled them, place them in cold water, as is done with potatoes. Cut them into slices about a fifth of an inch in thickness, and fry for a few minutes in butter with a couple of small chopped onions or shallots. Then place them in a saucepan with a pint of water, a teaspoonful of salt, and a little black pepper. Boil for about an hour till the vegetables are quite tender. Rub through a hair sieve, and add half a pint of milk and a teacupful of cream. Bring again to the boil, pour into a tureen, and serve with grated cheese.

\section{To Boil Artichokes}

Peel them and place in cold salted water as above, then place them in a saucepan of salted boiling water, and 
boil for twenty minutes. Drain them and serve with a simple sauce.

Instead of being served as a plain vegetable, the boiled artichokes may be mashed with a little butter, well-beaten egg, pepper and salt, placed in a buttered pie-dish, surmounted with a layer of grated cheese, and baked. Or the artichokes, when nearly boiled, may be cut into quarter inch slices, dipped in butter, and fried to a pale brown colour, which will take from five to ten minutes. Artichokes may be baked in butter (an ounce to six tubers) in a hot oven, the time occupied being from twenty-five to forty-five minutes. Keep well basted and season with salt and pepper.

\section{OnIONS AND LEEKS}

In his "Queen of the Air," Ruskin attributes the degradation of peasant life very largely to the use of the rank-scented onion and garlic. This doctrine is, of course, merely ridiculous, but it is in accordance with our national traditions, for throughout English literature we find frequent references to the grossness of the odours of these herbs. One recalls Bottom's directions to the clowns : "Most dear actors, eat no onions nor garlic, for we are to utter sweet breath"; and Hotspur's : "I had rather live with cheese and garlic in a windmill." But it was in no carping spirit of criticism that the Israelites muttered regretfully, "We remember the garlic we did eat in Egypt," and indeed, onions and garlic were highly ranked both as delicacies and as healalls many thousand years before the birth of Christ. So sacred was the position of the onion in ancient Egypt that Juvenal evidently had the idea that it was considered too sacred to be eaten.

"Porrum et caepe nefas violare, aut frangere morsu." 
"Onions as a relish to the wine" were among the few dainties placed before Nestor by Hecamede, and a jar of onions was one of the wedding presents received by Iphicrates.

The common onion has been found wild in Beluchistan and the countries adjoining, whilst the spring onion has been discovered wild in Siberia, leeks in Algeria and many other places, and chives commonly throughout Europe and North America. The onion was introduced into England at a very early period, though the shallot and the spring onion were not grown in this country before the sixteenth century. That, even in the time of Chaucer, a taste for onions was scarcely reckoned a mark of elegance is shown by his including it among the possessions of the Sompnour:-

"Wel loved he garleek, oynouns, and ek leekes."

The onion has had a lengthy career as an instrument of divination, and $\mathrm{Mr}$ Folkard, in his "Plant Lore and Legends," quotes an old verse illustrative of one of its uses:-

"In these same days young wanton gyrles that meet for marriage be

Doe search to know the names of them that shall their husbands be ;

Four onyons, five, or eight they take, and make in every one

Such names as they do fancie most, and best to think upon.

Then nere the chimney them they set, and that same onyon then

'That firste doth sproute doth surely bear the name of their good man."

As with most other pungently odorous plants, onions, leeks, and garlic have been-and still are-commonly reputed as givers of health and curers of many ills.

"Eat Leeks in Lide, and Ramsins (i.e. Garlic) in May, And all the year after physitians may play."

says one old couplet, but Gerard took quite another view : "The onion being eaten, yea though it be boiled, causeth headach, hurteth the eies and maketh a man dimsighted, dulleth the senses, and provoketh overmuch sleep, especially being eaten rawe." 


\section{To bake Onions}

Take any of the milder flavoured onions of good size and, having removed the outer coats, boil them for about forty-five minutes in water. Dry the onions with a cloth, place them on a baking dish, surmount each with a small piece of butter, cover with buttered paper, and bake for an hour. Serve with Beurre fondu, or plain butter. Season with salt and pepper.

\section{To stew Onions,}

peel them and place them in stock (two quarts to six large onions) seasoned with salt and pepper. Allow to simmer until they are quite tender. Reduce the stock, pour it over the onions, and serve.

\section{Onions and Cheese}

Take some large Spanish onions, skin them and boil them until they are quite soft. Drain them in a colander, and then pass them through a sieve. Place the mashed onions in a pan together with (to each onion) an ounce of butter, an ounce of grated cheese, and a little pepper and salt. Allow the mixture to simmer for a few minutes, stirring the while, and then serve.

Instead of placing the pulped onions in a stewpan, they may be placed with the butter, pepper and salt, and a little stock or milk (two tablespoonfuls to each onion) in a pie-dish, the cheese being grated over the surface, and placed in the oven till baked a nice brown.

\section{To stew Leeks,}

cut them into pieces three inches in length and place them in boiling salted water for a few minutes. Drain off the water and add a minimum of good stock. Boil till quite tender, and serve. If the leeks be removed from the pan before they are quite cooked, 
placed in a pie-dish, covered with a grating of cheese, and baked in the oven, a very pleasant dish is obtained.

In Cornwall and many other parts of England a popular dish is that known as

\section{Leeky Broth.}

Take a medium-sized cabbage and two medium-sized leeks and cut them into shreds. Place them in a stewpan together with two quarts of stock or haricot water, a dessertspoonful of salt, and a saltspoonful of pepper. Boil for two hours and serve unstrained. A few lentils or haricots materially add to the nutritive value of this broth.

\section{Potatoes}

In that granary of interesting information, Canon Ellacombe's "Plant Lore of Shakspere," two passages are quoted from the plays as containing "almost the earliest notice of potatoes after their introduction into England." As, however, Gerard knew potatoes only as rareties, it is probable that Shakspere's references were to the Sweet or Spanish Potatoes, which had for some time previously been cultivated in Spain and Portugal, and imported thence into England. These latter are the tubers of a member of Convolvulus family, whereas the ordinary potato belongs to the Solanacex, to which also belong such powerfully poisonous plants as the Deadly Nightshade and the Henbane. In the frontispiece to his "Herbal," published in 1597, Gerard is figured with a potato in his hand. It occurs wild in Chili, and its cultivation had spread to the neighbouring parts of America long before the discovery of that continent by Europeans. It was introduced into Europe almost coincidentally by certain Spanish adventurers, and by Sir Walter Raleigh, who took some roots to 
Ireland about the year I584, giving some to his own gardener at Youghal, and others to the grandfather of S. R. Southwell, who reported to the Fellows of the Royal Society that his grandfather was the first to grow potatoes in Ireland. The vegetable did not immediately win great favour, and we find that Evelyn's sole practical advice in the "Kalendarium Hortense" on the planting of potatoes is given in one line of the February directions: "And plant potatoes in your worst ground;" the only other reference to the vegetable being in the section for November, where he writes: "Take up your potatoes for winter spending; there will enough remain for stock, tho' never so exactly gathered." In Worlidge's "Systema Agriculturæ," of which the second edition-the one of which I possess a copy-was published in 1675, he says of potatoes: "These are very usual in foreign parts, and are planted in several places of this country to a very good advantage; . . . they are commonly eaten either buttered, or in milk. I do not hear that it hath been as yet essayed, whether they may not be propagated in great quantities for food for swine, or other cattle." Even as late as I7I9 we find Bradly writing of potatoes that "they are of less note than horse-radish, radish scorzoners, beets and skirret; but as they are not without their admirers, I will not pass them by in silence."

In the Literary Magazine for May 1757, appeared a letter from a Staffordshire farmer, strongly urging the more extended culture of potatoes. "At a time when the nation is in such distress for want both of corn and butcher's meat, it may not be amiss to point out a method by which people may be kept, and kept well, without any corn or meat at all. . . . I plant every year four acres of potatoes, which answer all the purposes of wheat. For with them we make 
puddings and pies, and boil or roast them for bread; and we like them better than your bread. . . . In my family we keep them always boiled in the house, and in the morning my people eat milk and potatoes. At dinner they have generally bacon or hung beef and potatoes, and for supper we mash our potatoes and add milk and salt to make a pudding; and sometimes for change we have potatoes fry'd in the fat that is left in the pan after frying bacon or beef; and we also make pies with potatoes and mutton or other meat. - . Many of my neighbours eat - nothing but potatoes the year round, and are very healthy and strong. A bushel of potatoes generally sells with us for about eightpence or ninepence, and is sufficient to keep a man a fortnight who eats nothing else." Here.is indeed enthusiasm.

From about the date of this letter onwards potatoes grew steadily in popularity. Hanbury, in his "Complete Body of Planting and Gardening," published in I77I, wrote that "they are universally admired. High and low, rich and poor, covet them at their tables. In Ireland and some other countries they are become the staple sustenance of the common people. With the former they seem perfectly to agree, though all will not allow them to be entirely wholesome; and a dullness is said to attend the constant eating of them. Most allow that they are a cloy to genius; and the Irish, who are undoubtedly hardy in the field, are said to be an heavy sort of people, probably on account of their immoderate use of potatoes."

\section{To boil Potatoes}

Ability to boil potatoes as potatoes should be boiled has been wisely proposed as the index of a good cook. Poor sorts of potatoes, or poor specimens of good varieties, cannot by any culinary ingenuity be converted 
into the delicious dish which boiled potatoes may afford. In dealing with new potatoes freshly dug from the soil, first wash and vigorously rub them in cold water, and then place them in a pan of boiling salted water ( $a$ teaspoonful to a quart), and boil for about a quarter of an hour or twenty minutes. Then pour off the water, again place the saucepan on the fire, having removed the lid of the pan, and keep the potatoes on the shake for about five minutes. They should be served on a napkin placed in a hot vegetable dish, and should be covered only with a warm napkin, or adequate evaporation will be impossible.

Old potatoes also are best cooked in their skins, but they should be placed in a pan of cold salted water and boiled for about twenty minutes, testing their condition with a fork. They should be dried and served in the same way as new potatoes, though, if preferred, the skins may be removed after cooking and before serving. The ordinary method of peeling potatoes before cooking them is destructive of all flavour and diminutive of food value. Instead of being boiled, potatoes may be steamed, the other steps in the preparation being similar. In order that all the tubers may be cooked equally, those . only of approximately the same size should be cooked together.

\section{To fry Potatoes}

which have been previously boiled, they should (if old) be peeled, and then cut into slices about a quarter of an inch in thickness. The slices are then to be placed in the boiling oil (several inches deep) of the sauté-pan over a good fire, and kept moving till they assume a rich golden brown colour. They should then be drained on blotting paper or a wire sieve, and slightly salted, a little pepper and finely-minced parsley being also sprinkled over them 
if desired. The slices of potato may be dipped in savoury egg and bread crumbs before being placed in the sauté-pan.

\section{Mashed Potatoes}

is made by boiling a dozen potatoes as directed, and, having thoroughly dried them and broken them each into two parts, squeezing the contents from the skins into a pan containing two ounces of butter, a quarter of a pint of nearly boiling milk, and a little pepper and salt, the whole being thoroughly mixed and smoothed by being beaten with a fork.

\section{To bake Potatoes}

Of all the methods of cooking potatoes, none are more delicious and none so full of romance as that of baking. No one can have lived long and freely in London without having discovered the infinite charm of the fruit of the night potato stall, and there are few country boys but know the joy yielded by the potato baked in the ashes of the bonfire when the more violent glow of the flames has departed. In this way, or equally well in an ordinary Dutch oven, may baked potatoes of the highest excellence be prepared. Choose large potatoes, bake for about two hours until the outer jacket bursts. A little salt, pepper and butter, or cheese (the latter making delicious combinations with starchy foods of all kinds), should be served with them.

\section{Potato Fritters}

The more complicated dishes of which potatoes form the chief ingredients are almost infinite in number. A pleasant way of frying potatoes is to boil a dozen moderate-sized tubers, pound them when cold, with half a small cupful of minced parsley, a little mace or 


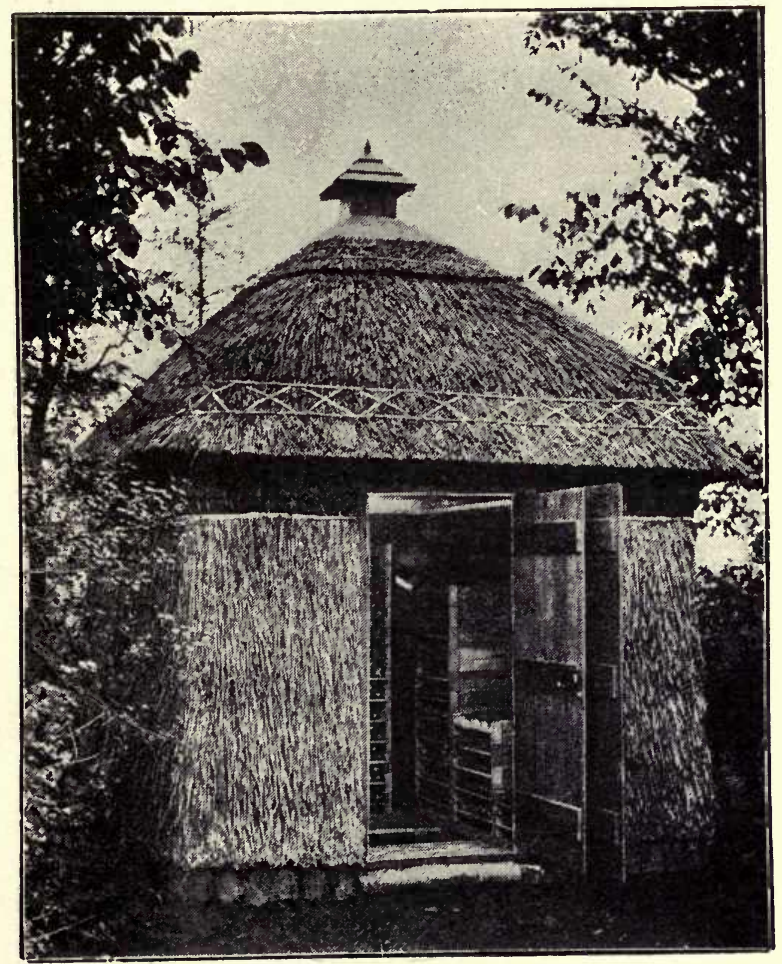

AMATEUR'S SHED FOR STORING POTATOES 


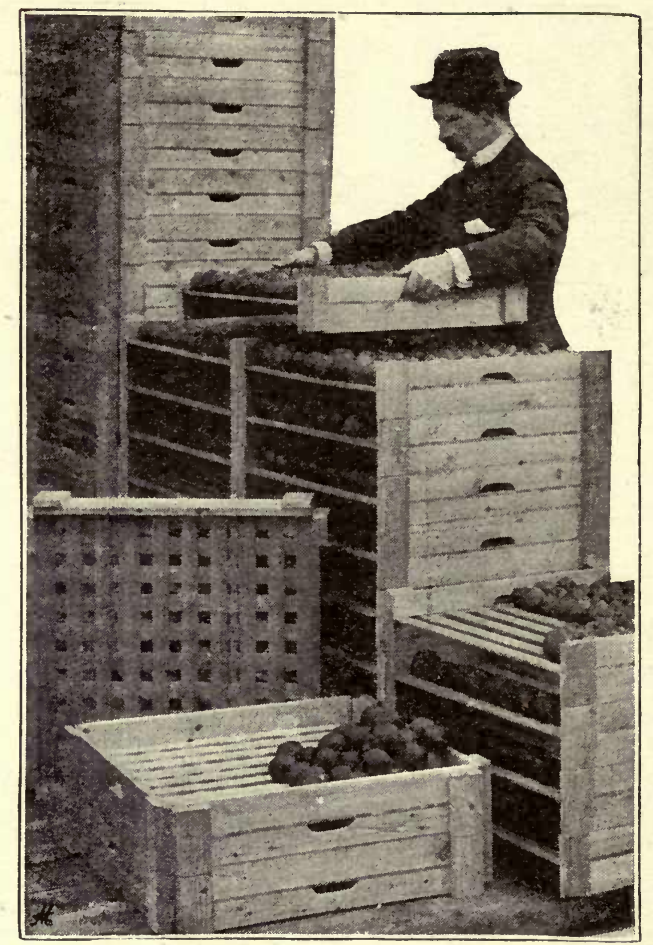

ORR'S STORING TRAYS

(showing method of stacking) 


$$
8
$$


cinnamon, a little pepper, and a little salt, making the mixture into small fritters and frying in butter or oil till golden. A couple of well-beaten eggs and a teacupful of cream may be mixed with the pounded potatoes, and the flavouring spices and herbs may be varied to any extent.

\section{Potatoes and Cheese}

A good dish is made by taking four moderatesized potatoes, peeling them and cutting them into slices a quarter of an inch in thickness, placing these in a well-buttered baking dish, covering with a mixture of two ounces of grated cheese, half-a-dozen boiled and minced onions, an ounce of butter, and a little salt, pepper and sage, and baking for nearly two hours until thoroughly cooked and browned.

\section{Purée of Potatoes}

Cold boiled potatoes may be pleasantly utilised by mincing them with cold boiled spinach, cabbage or turnip-tops, and frying the mixture with a little butter until a nice brown. They may be used in the cold state either as a salad, or by being passed through a fine sieve and mixed with a little pepper, salt, minced parsley, some cream (a breakfast-cupful to four moderate-sized potatoes), béchamel sauce (a tea-cupful), with gelatine (an ounce to four potatoes) dissolved therein, the resulting mixture to be placed on ice, and served as a set purée.

\section{PeAs}

Even more delicious to most palates than asparagus itself, green peas have long been almost universally popular in England.

"Dig garden, stroy mallow, now may ye at ease, And set (as a daintie) thy runcival pease" 
were among the January "Points" of Tusser, and that there were peas and peas is shown by the record in the privy purse expenses of Henry VIII.: "Paid to a man in reward for bringing pescodds to the King's grace, iiijs. viiid."

Worlidge, in his "Systema Agriculturae: Published for the Common Good," of which the second edition appeared in I675, enumerates "several sorts of Garden Pease sown or planted in this kingdom, some approved of for their being early ripe, and some for their pleasant taste; others from their being late ripe succeeding the other."

Garden peas have been discovered in old Swiss lakedwellings of the bronze age, and they were among the vegetables cultivated in ancient Greece, but their original habitat is uncertain. By some the garden pea is thought to be but a variety of Pisum arvense, the field pea, which is found wild in Italy, but this seems to be doubtful. Peas figured honourably in German mythology and were consecrated to Thor, who was supposed, being a god of some gastronomic taste, to have a weakness for this vegetable.

Shakspere's "Squash" referred to young pods before the formation of Peas-or Peason, as the plural was almost invariably written previous to the seventeenth century: "Not yet old enough to be a man, nor young enough for a boy: as a Squash is before 'tis a Peascod, or a Codling when 'tis almost an Apple." Most of the early English references to Pese and Peason are concerned with the dried kinds, though even in Norman times there are records of green peas being eaten at Barking Nunnery and elsewhere.

\section{To boil Peas}

There is no room for doubt as to the best method of cooking peas, providing they be of a good variety, 
freshly picked, and in good condition. Tender green peas should be placed in a stewpan containing only just sufficient salted (a teaspoonful to the pint) boiling water to cover them. Add nothing else, neither soda, nor mint, nor yolks of eggs. Boil quickly for about ten minutes until the peas are tender, the lid of the pan being kept off the while. Drain in a colander, and serve in a hot vegetable dish. That is the one and only way in which the better sorts of peas-especially the better sorts of marrowfats-should be cooked. But there are peas other than the best, and even the most fastidious worshipper of the simple will allow some attempts at improvement in dealing with such. For example, the addition of a few leaves of mint or parsley and a little butter (an ounce to the pint) to the water in the stewpan may be tried, or even a small onion may be boiled with the peas.

\section{To cook Old Peas}

Old peas are best cooked by being placed, together with a little butter and flavourings as suggested above, in a screw-stoppered jar, which is to be set in a stewpan of water kept boiling for about threequarters of an hour. A lump of sugar is commonly added; and sometimes a lettuce, cut up into inch squares, is boiled with the peas.

More complicated dishes may be accomplished by adding to the peas cooked in any of the above ways the yolks of eggs well beaten up with cream (two eggs and four tablespoonfuls of cream to a pound of peas), care being taken to avoid the boiling point.

Old peas boiled with a minimum of water, a little butter, ham, herbs, pepper and salt, subsequently improved by the addition of the egg and cream mixture, afford a pleasant dish. 


\section{Pea Croquettes}

Peas, thoroughly cooked and well drained, may be beaten to a pulp, mixed with a little butter, pepper, salt, cooked ham finely minced, herbs and breadcrumbs, made into little croquettes, dipped in egg and breadcrumbs and fried in boiling oil. Or the cooked and pulped peas may be rubbed through a sieve, mixed with butter, cream, salt and pepper, and served as a purée. Pease-pudding may be made either with green peas or dried split ones. In either case boil them till tender, drain them and pass them through a sieve. Add and thoroughly mix a little cinnamon, pepper, salt and butter (an ounce to the pint), together with a sliced onion and some well-beaten eggs (three to the pint). Place the mixture in a screw-stoppered jar, well-buttered, and cook in a bain-marie.

\section{To cook Pea-pods}

The pods of peas are usually wasted in this country, although they are lacking neither in nourishment nor flavour. In the case of very young pods they may be cooked entire in salted boiling water, as directed in dealing with shelled peas; but in the case of older pods they should be trimmed, sliced, and boiled for a considerable time till thoroughly tender. Even when the pods themselves are not cared for, the water in which they have been boiled goes towards the making of stock for vegetable soup.

\section{Dried Split Peas,}

and, what are very much to be preferred, dried green peas, are among the most concentrated and valuable of foods. A pennyworth of dried peas contains in actual flesh-forming constituents the equivalent of at least a pound of 'beef-steak, a fact 
which authors who complain of their publishers' terms would do well to bear in mind. Dried peas require a little more care in their cooking and preparation for the table than it is usually their destiny to receive. They should be well washed in several waters and then left to soak in cold water for at least six hours. It is when they appear as pea-soup that dried peas deserve best the encomium of the thrifty gastronome.

\section{To make Pea-soup,}

take a pint of soaked peas and place them, together with a sliced onion, a sliced carrot, two sliced turnips, a little celery, some thyme, mint and sage or other herbs, a dozen peppercorns, a teaspoonful of salt and three pints of water, in a large saucepan. Boil until the peas are tender, which will take about two hours. Strain and pass the vegetables through a sieve, and add the purée to the broth. It is a good plan to fry the sliced vegetables in a little butter, previously to placing them in the saucepan. Mrs Roundell advises that, just before the pan is taken off the fire, a little cream or the yolk of an egg beaten with milk be added to the soup, and either of these certainly is a pleasant supplement. Fresh green peas may be used to make soup in somewhat like manner, but, in their case, soaking is not to be practised, nor is so long a period of boiling required.

\section{BEANS}

Few vegetables, as indeed few plants of any class, surpass in decorative value the sturdy, self-supporting broad bean, with its fragrant, creamy flowers; or its scarlet-blooming relative, the twining kidney bean. Among the ancient Egyptians, however, so far from being an object meet for admiration, the bean was considered an unclean thing, evil even if but looked 
upon; and the fear of the scent of bean flowers has lasted in rural England down to quite recent times. On the other hand the Greeks and Romans held beans in high honour, many believing that they contained the souls of the departed. However, there were others whose admiration took a more practical form, and Pliny reports that beans were eaten boiled, mixed with flour and baked, served with vinegar as a bors-d'cuvre, and boiled in the green pod. Pliny also tells us that Roman farmers were accustomed to plough the green bean plants into the soil with a view of rendering it richer and more fertile, thus forecasting our recent discovery of the power of leguminous plants to obtain nitrogen from the air.

The broad bean was early introduced into England, though its great value as food does not appear to have been at first recognised, for we find Chaucer saying :-

" None other lif, sayd he, is worth a Bene."

The economic value of the bean, however, gradually won recognition, and Fuller quotes a common saying of his time: "Shake a Leicestershire yeoman by the collar, and you shall hear the beans rattle in his belly"; and adds that the "yeomen smile at what is said to rattle in their bellies, whilst they know good silver ringeth in their pockets."

The use of the bean in Twelfth Night elections is well known, but it is interesting to find that the Greeks and Romans used it extensively as an instrument of the ballot. Its use at the mayoral elections in one of the smaller towns of Leicestershire reduced the expenses of contesting candidates to a minimum. The would-be mayors having duly seated themselves so as to form a semi-circular arc, each holding between his knees his inverted hat full of beans, a pig was carefully driven into their midst who by his first choice decided the election. 
The Dutch Kidney Bean, or Haricot, although cultivated in France in the ninth century, was only introduced into England at about the beginning of the sixteenth century, the scarlet runner being introduced a hundred years later. Gerard described several kinds of "kidney beans of Brasile," or "Faselles," and said that their "fruit and pods boiled together before they be ripe, and so eaten, are exceedingly delicate meat."

\section{To boil Broad Beans,}

the water should be boiling vigorously when the shelled beans (which should be much younger than the usual age at which they are cooked) are introduced. A salt-spoonful of salt should be added to a quart of water. The beans should be boiled for about twenty to twenty-five minutes, until the skins crack. They may then be drained from water and served with butter, sauce Hollandaise, or Beurre fondu; or the beans may be taken from the pan, and their skins rubbed off by means of a warm cloth, the centres being heated in a simple sauce, or minced with herbs and butter.

\section{Beans and Onions}

An excellent bean dish is the following: Fry in a little butter a moderate-sized onion, with a sprig or two of sweet herbs. Place these, together with a quart of young broad beans which have been shelled, in a saucepan containing a quart of boiling water. Season with pepper and salt, and, if desired, add also a few tomatoes. Boil gently for about three quarters of an hour, adding a little more water if needed, and serve. Or a little ham and a tumbler of wine with a couple of ounces of sugar may be added, instead of the tomatoes, about twenty minutes before serving. 


\section{Beans and Bacon,}

being one of those combinations whose rightness depends, not on the vagaries of fashion, but on physiological fact, retains its ancient place in the favour of hungry men. Mrs Glasse gives to the preparation of this dish the space which it deserves. "When you dress beans and bacon," said she, "boil the bacon by itself, and the beans by themselves, for the bacon will spoil the colour of the beans. Always throw some salt into the water, and some parsley, nicely picked. When the beans are cooked enough (which you will know by their being tender) throw them into a cullender to drain. Take up the bacon and skin it; throw some raspings of bread over the top, and if you have an iron make it red hot and hold over it, to brown the top of the bacon; if you have not one, set it before the fire to brown. Lay the beans in the dish, and the bacon in the middle on the top, and send them to table with parsley and butter in a basin."

Mrs Roundell's directions are, as usual, wise and concisely expressed. "Choose a pig's cheek which is not dry and hard, otherwise it must be soaked for four hours, and will not be nearly so good as if cooked when fresh. Put it in a saucepan with five quarts of water, and let it simmer gently, allowing twenty minutes for each pound of meat. Shell two pounds of Broad Beans. Half-anhour before the pig's cheek is done take out two quarts of the liquid in which it is boiling, and replace instantly with two quarts of boiling water. Put the two quarts of liquid in another pan, throw in the Broad Beans, and boil them in the liquid for from twenty minutes to halfan-hour. Serve the pig's cheek in a large hot dish. Moisten the Broad Beans with a spoonful of the liquid, and put some of them round the pig's cheek in the dish, 


\section{IO4 THE BOOK OF VEGETABLES}

the rest in a vegetable dish. The remainder of the liquid makes excellent second stock."

Another old favourite dish is

\section{Baked Beans and Pork.}

Put a knuckle of pork and a little salt into an earthenware jar which holds five quarts. Then fill it half full with shelled Broad Beans, and add cold water up to the brim. Put on the lid of the jar, which must have a hole in it to allow the steam to escape. Set the jar in the oven, and let it remain there twelve hours. The beans and meat will be perfectly cooked by that time in rich gravy. The gravy will form a jelly when cold.

Like Broad Beans,

\section{French Beans}

also should be used at a much younger stage than is usually the case. They do not then require stringing, which process, as Mrs Roundell points out, lets out some of the flavour. Neither, unless they are very old, should French Beans be sliced. They should be boiled, in exactly the same way as directed for shelled Broad Beans, until they are tender. Serve with Beurre fondu, or Sauce Hollandaise. Unless they are too old, French Beans should never be cooked in any other way than the above; but old ones may be cooked by slicing them and stewing them in a minimum of well-seasoned stock until tender, finally

- thickening the stock with egg and pouring it over them. A number of excellent Italian recipes are given in "Leaves from our Tuscan Kitchen," by Janet Ross. This is a recipe for

Beans alla Crema.

Take a pint of French Beans which have been nearly cooked by the process of boiling, and, having dried them, 


\section{HISTORY AND COOKERY}

fry them in butter. Mix a teacupful of cream, an egg, some grated cheese, and some allspice well together in a saucepan, then add some lemon juice, a little white wine vinegar, and boil. Pour this sauce over the beans, mix well, and serve up hot.

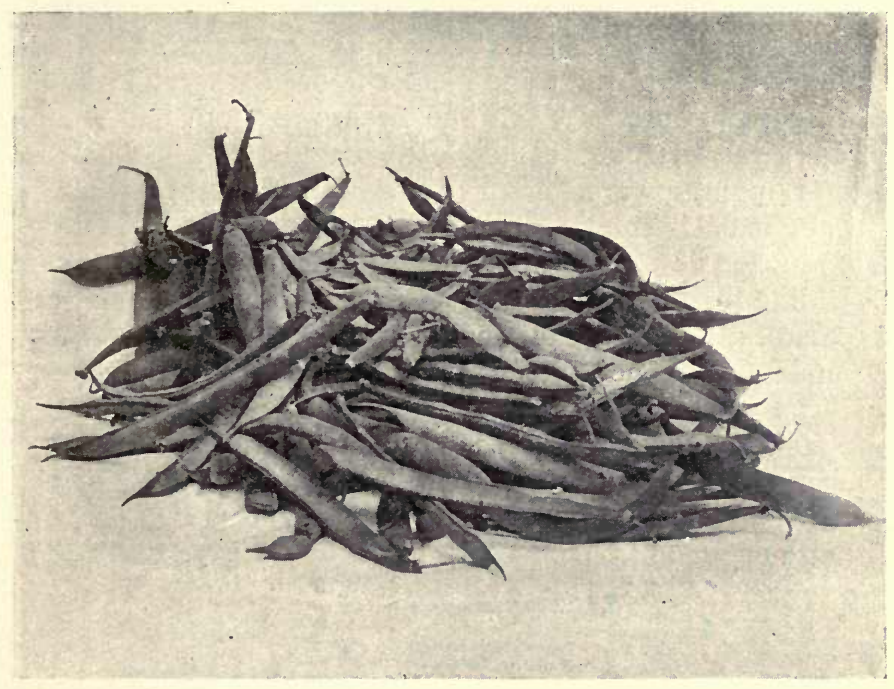

DWARF BEAN-CANADIAN WONDER

\section{Beans allo Zabajone}

is prepared thus. Clean and remove the strings from two quarts of French Beans, and put them into cold water; then boil and strain, and lay them in a dish. Put two yolks of eggs, two tablespoonfuls of sugar, two of white wine vinegar, and two of water into a saucepan on a slow fire. Mix and heat, but do not allow it to boil. Pour the sauce over the beans and serve hot. 


\section{THE BOOK OF VEGETABLES}

\section{Haricot Beans,}

or, indeed, any of the beans, in the mature and dried state, freed from their pods, are among the most valuable and nutritious of articles of food. They should be washed and then soaked in cold water for the whole of the night previous to cooking them. For each pint of soaked beans place in a saucepan two quarts of cold water and place the beans therein. Boil for three hours. When the beans are about half done add a dessertspoonful of salt. Strain in a colander, reserving the water in which the beans have been boiled to be used as stock. They may be served with Beurre fondu, parsley and butter, or with bacon.

Mixed with sliced carrots, turnips and onions, celery or tomatoes, haricot beans make a nutritious and pleasant soup. Allow one pint of haricots to two quarts of water, season with pepper and salt, and boil for two hours.

It may interest the impecunious to learn, that for one penny spent on haricots they may obtain six times as much nitrogen and twenty times as much carbon as for the same amount spent on beef. 



\section{DAY USE \\ RETURN TO DESK FROM WHICH BORROWED

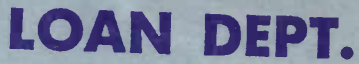

This book is due on the last date stamped below, or on the date to which renewed.

Renewed books are subject to immediate recall.

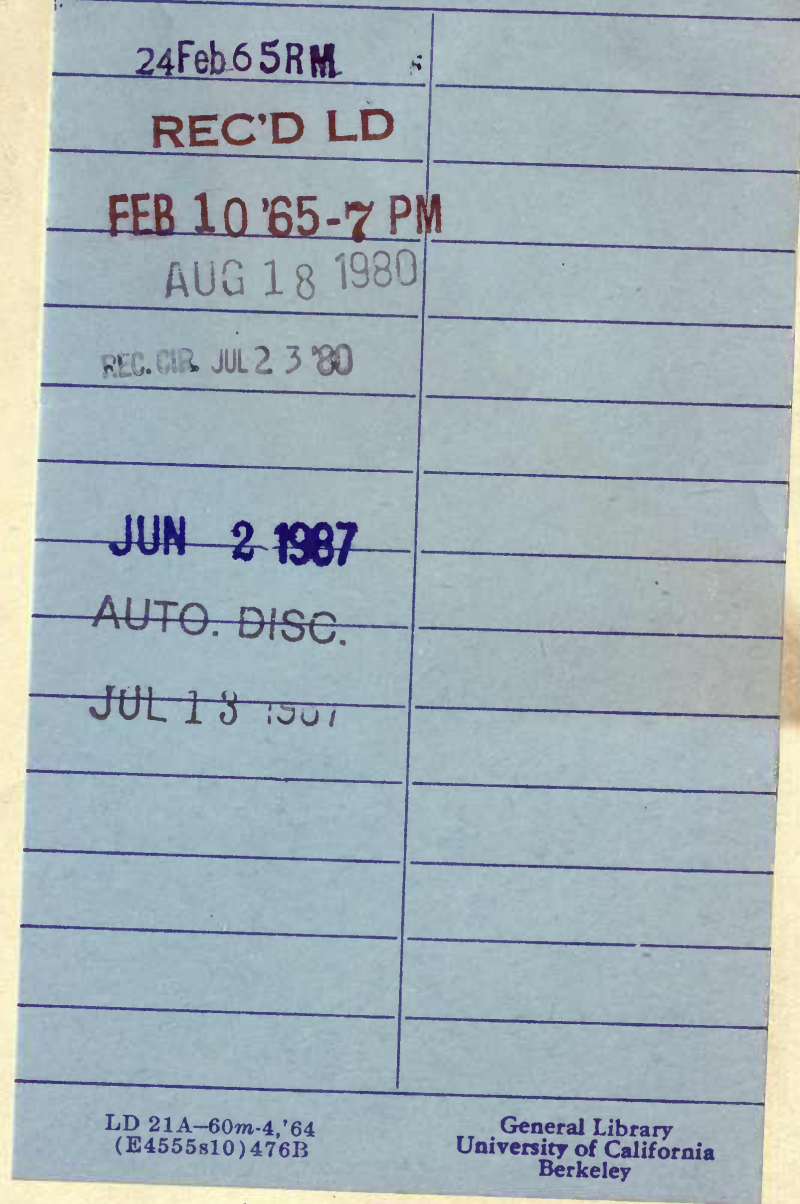




\section{GENERAL LIBRARY - U.C. BERKELEY}
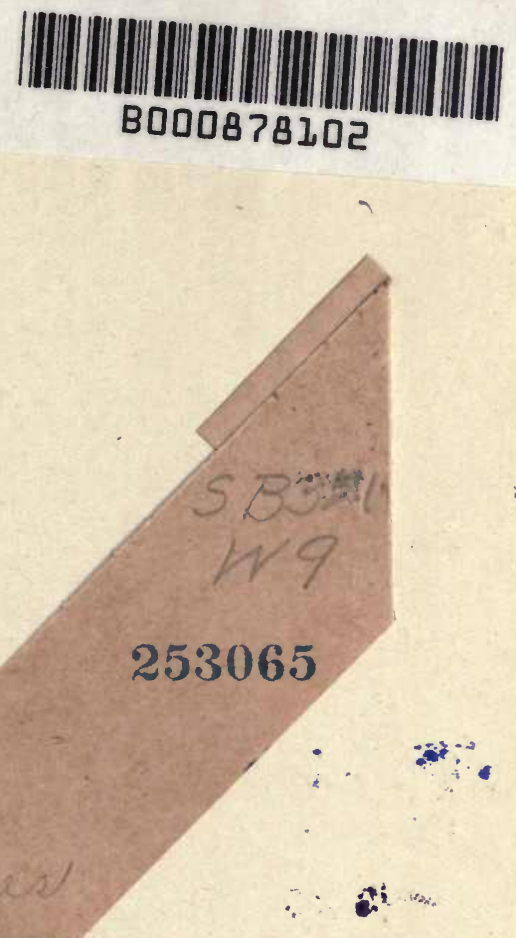


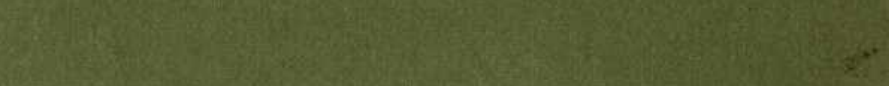

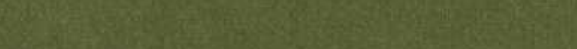

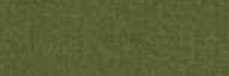

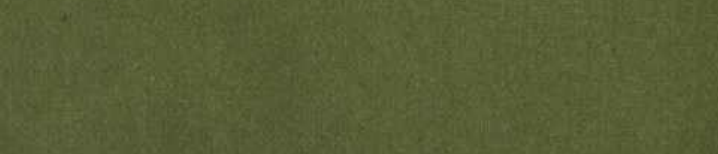

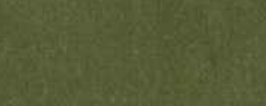

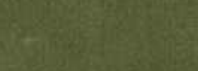

(x)

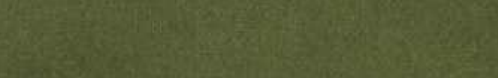

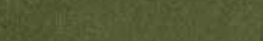

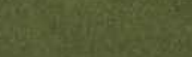
$\sqrt{52}$

站要 angesing 80

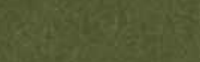
$6 \frac{1}{2}$ 